"An exploratory analysis of quick service restaurants using tidyverse tools in R"

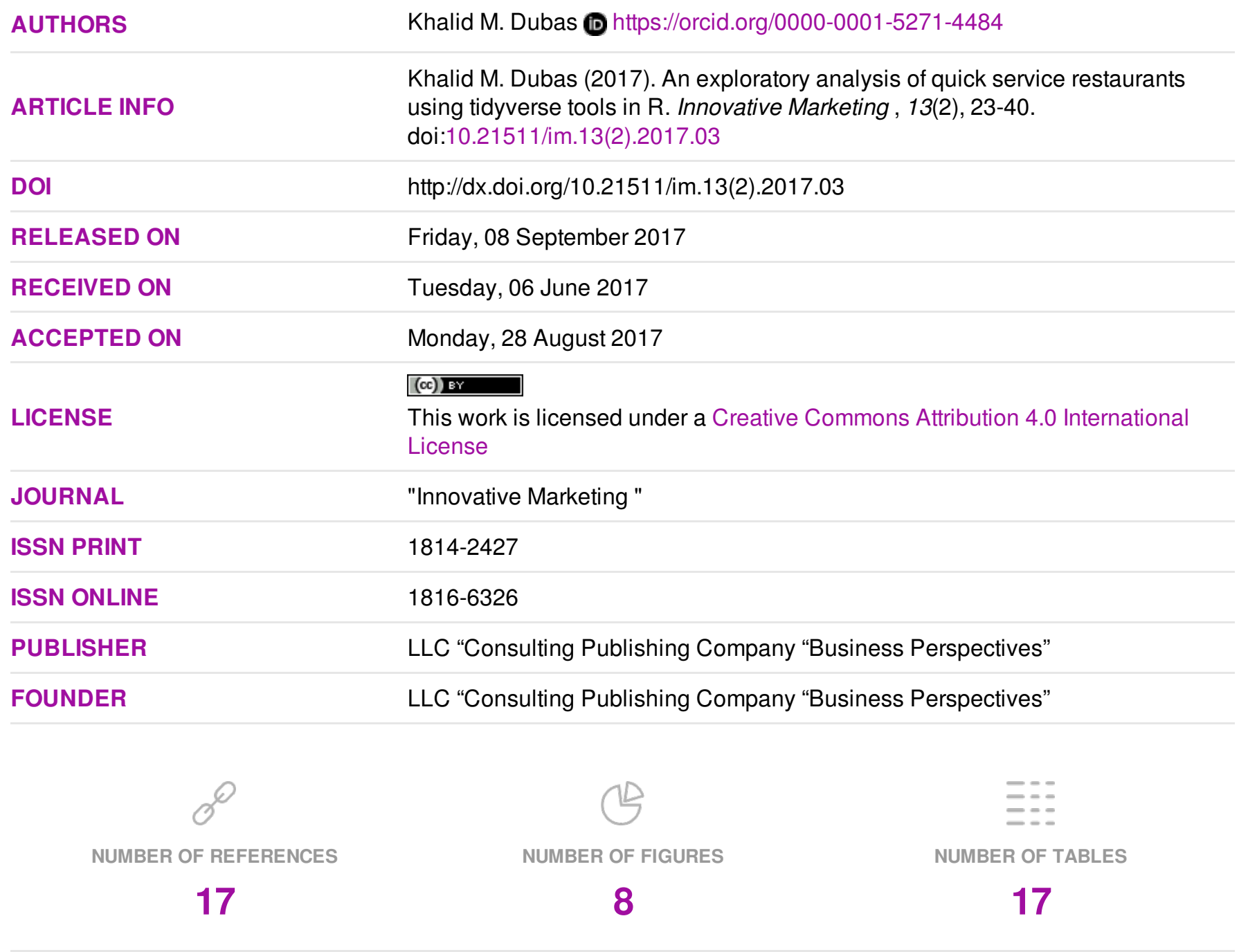

C The author(s) 2023. This publication is an open access article. 
Khalid M. Dubas (USA)

\title{
An exploratory analysis of quick service restaurants using tidyverse tools in $\mathrm{R}$
}

\begin{abstract}
This study presents an exploratory analysis of Quick Service Restaurants (QSR) industry in the US during 2015 by using publicly available data and open-source $\mathrm{R}$ software. The data analysis framework and tools utilized here were developed primarily by Hadley Wickham and are included in his tidyverse package in R. This data analysis framework consists of data import, data wrangeling, data exploration (tranformation, visualization, and modeling), and communication of results (Wickham \& Grolemund, 2016). These steps are illustrated by exploring the relationship between sales, customer satisfaction, and other characteristics of 65 QSR restaurants in the US. In order to facilitate reproduction and replication of this study, the dataset as well as the $\mathrm{R}$ code are included in this study.
\end{abstract}

Keywords: data science, $\mathrm{R}$ language and enviornment, tidyverse, visualization, transformation, model building, quick service restaurants, reproducible research.

JEL Classification: M31.

Received on: $6^{\text {th }}$ of June, 2017.

Accepted on: $28^{\text {th }}$ of August, 2017.

\section{Introduction}

It is important for a scientific study to be reproducible by the reader of the study. This ensures reliability of the study's findings and helps a discipline grow through replication of the study for different datasets and different settings thus accumulating independently verified scientific knowledge. For this purpose, the data as well as the code for a study should be publicly available. This favors the use of open source software for analysis since a proprietary software would limit access to the reader due to licensing requirements.

While the base R software (The R Foundation, n.d.) is updated a few times a year, there were over 10000 user-contributed packges at the Comprehensive $\mathrm{R}$ Archieve Network (CRAN) at the time of writing of this document. These user-contributed packages are frequently updated and new packages are added to CRAN at an exponential rate. Most new developments in $\mathrm{R}$ occur through these usercoontributed packages. One recent major addition to $\mathrm{R}$ is the tidyverse set of packages (Wickham, 2016; Wickham \& Grolemund, 2017). The tidyverse is a set of packages that share a common design philosophy of Hadley Wickham and provide a consistent framework for data science with R. There are four basic principles to a tidy API (Wickham, 2017).

1. Reuse existing data structures.

2. Compose simple functions with the pipe.

3. Embrace functional programming, and

4. Design for humans.

(C) Limited Liability Company "Consulting Publishing Company "Business Perspectives", 2017.

Khalid M. Dubas, Dr., Professor of Marketing, University of Mount Olive, USA.
The tidyverse significantly extends the capabilities of $\mathrm{R}$ for data science and library (tidyverse) loads the following core packages ("Tidyverse packages", n.d.):

- readr for data importing;

- tibble for a modern way of data representation;

- tidyr for data tidying;

- dplyr for data manipulation;

- ggplot2 for data visualization; and

- purrr for functional programming.

Tidyverse's capabilities are extended by other tools and specialized packages. Here are the main tools and packages as they relate to various stages of data science ("tidyverse", n.d.):

- Workflow - scripts, projects, etc.

- Import-readr, readxl, heaven, etc.

- Wrangle - tibble, tidyr, dplyr, stringr, forcats, lubridate, hms, blob, etc.

- Visualize - ggplot2.

- Program - purrr, rlang, magrittr, glue, etc.

- Model - modelr, purrr, broom, etc.

- Communicate - RMarkdown, ggplot2, etc.

Fig. 1 shows some extended tidyverse packages.

While the best place to learn about tidyverse is Wickham \& Grolemund (2017), other resources are also available to enhance one's knowledge about tidyverse (Held, 2017; Levy, 2016; Wickham, 2016; R Views, 2017; and "The tidyverse: dplyr, ggplot2, and friends", n.d).

Purpose and scope. The purpose of this study is to illustrate the use of tidyverse tools in $\mathrm{R}$ for data science. The complete data analysis framework is presented here by using publicly available data on 65 Quick Service Restaurants 
(QSR) in the US in 2015. This study, while illustrative and exploratory in nature, also evaluates the characteristics of different segments of QSR restaurants in the US and explores the factors that influence restaurant sales.

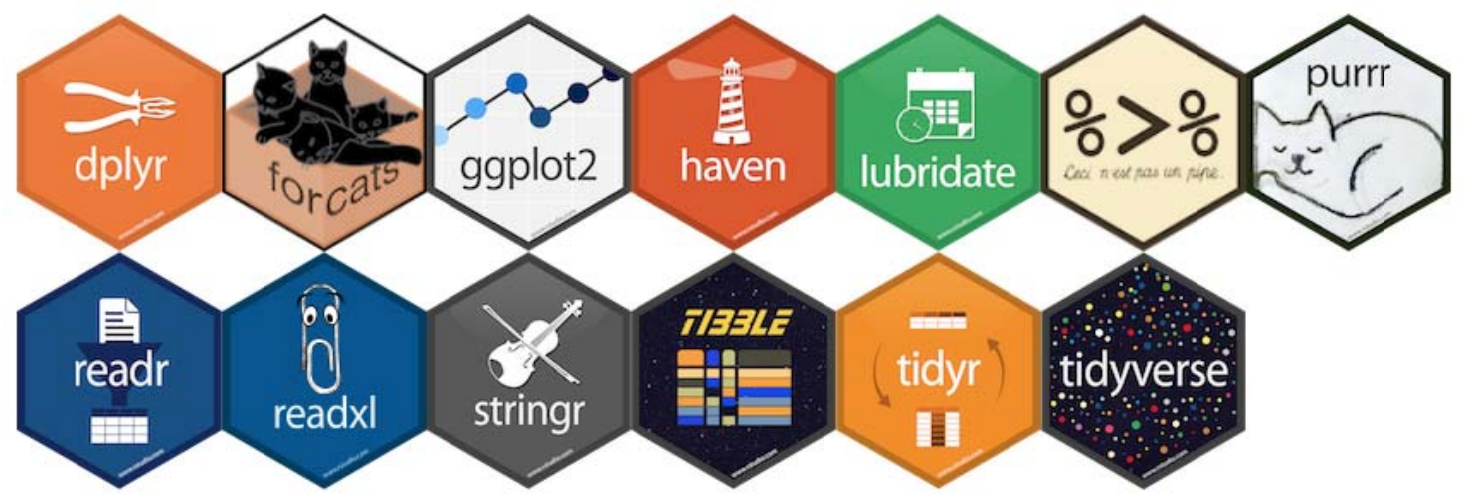

Fig. 1. The tidyverse packages

Reserch questions. This study addresses these research questions:

1. What are the main segments of the U.S. QSR industry?

2. Who are the leaders in each QSR segment?

3. What factors influence the Sales of a QSR restaurant?

4. What factors influence the Sales of a QSR restaurant within each segment?

\section{Data import}

The tidyverse package was installed before importing data. The data file, qsr65, was imported using $\mathrm{R}$ and RStudio. This data file contains information about 65 Quick Service Restaurants (QSR) in the U.S. in 2015. All data, except American Customer Satisfaction Index (ACSI) for QSR were obtained from QSR, Inc. (2016). The data on 2015 ACSI for QSR were obtained from ACSI LLC (2017).

The data file includes the following variables:

- company - An American QSR;

- rank - The rank of Annual Sales in 2015;

- sales - 2015 U.S. System-wide Sales (\$ millions);

- acsi - American Customer Satisfaction Index for a QSR in 2015. $(0-100)$;

- segments - QSR segments in 2015. There were burger, chicken, sandwich, pizza, seafood, ethnic, and snack;

- seg_rank - The rank of a QSR in its segment;

- unit_avg - 2015 U.S. Average Sales per Unit (thousands);

- fr_units - Number of Franchised Units in 2015;

- co_units - Number of Company Units in 2015;

- change - Total Change in Units from 2014.
The data table was produced by kable function in the knitr package.

1.1. Research question \#1. What are the main segments of the US QSR industry?

Answer \#1. The first research question is answered by the data. There were seven QSR segments: burger, chicken, sandwich, pizza, seafood, ethnic, and snack.

1.2. Research question \#2. Who are the leaders in each QSR segment?

Answer \#2. The second research question is answered by the data. The leaders in each QSR segment were listed by seg rank: McDonald's (burger), Chick-fil-A (chicken), Subway (sandwich), Pizza Hut (pizza), Captain D's (seafood), Taco Bell (ethnic), and Starbucks (snack).

Research questions \#3 and \#4 are explored throughout the rest of this study.

\section{Data wrangling}

After importing the data file, qsr65, the measurement scales of variables were examined. It was noticed that two variables, sales and unit avg, were measured on a character scale since they represented sales in US dollars and included commas to facilitate reading of large numbers. Since these variables should have been measured on a numeric scale, they were converted to numeric scales. Their median values were calculated to check that they were properly transformend from a character scale to a numeric scale. The median sales were $\$ 776$ million and the median unit_avg sales were $\$ 1,123$ thousands. 
Table 1. Quick service restaurants (USA, 2015)

\begin{tabular}{|c|c|c|c|c|c|c|c|c|c|}
\hline Company & Rank & Sales & Asci & Segments & Seg_rank & Unit_avg & Fr_u & Co-u & Change \\
\hline Arby's & 16 & $\$ 3,540.00$ & 74 & Sandwich & 3 & $\$ 1,073.00$ & 2210 & 1004 & -12 \\
\hline Auntie Anne's & 49 & $\$ 529.20$ & NA & Snack & 7 & $\$ 500.10$ & 1238 & 14 & 59 \\
\hline Baskin-Robbins & 46 & $\$ 584.00$ & NA & Snack & 6 & $\$ 233.30$ & 2493 & 10 & 19 \\
\hline Bojangles' & 28 & $\$ 1,153.00$ & NA & Chicken & 5 & $\$ 1,838.70$ & 378 & 281 & 40 \\
\hline Boston Market & 44 & $\$ 617.90$ & NA & Chicken & 9 & $\$ 1,364.00$ & 5 & 453 & 2 \\
\hline Burger King & 4 & $\$ 9,530.00$ & 72 & Burger & 2 & $\$ 1,337.40$ & 7074 & 52 & -16 \\
\hline Captain D's & 48 & $\$ 531.70$ & NA & Seafood & 1 & $\$ 1,024.00$ & 238 & 272 & -1 \\
\hline Carl's Jr./Hardee's & 15 & $\$ 3,661.30$ & NA & Burger & 5 & $\$ 1,248.70$ & 2673 & 285 & 45 \\
\hline Charleys Philly Steaks & 65 & $\$ 334.10$ & NA & Sandwich & NA & $\$ 692.00$ & 503 & 48 & 17 \\
\hline Checkers/Rally's & 33 & $\$ 776.10$ & NA & Burger & 11 & $\$ 966.50$ & 505 & 324 & 25 \\
\hline Chick-fil-A & 8 & $\$ 6,825.90$ & 86 & Chicken & 1 & $\$ 3,977.30$ & 1646 & 337 & 96 \\
\hline Chipotle & 12 & $\$ 4,501.20$ & 83 & Ethnic & 2 & $\$ 2,424.00$ & 0 & 1971 & 216 \\
\hline Church's Chicken & 31 & $\$ 838.00$ & NA & Chicken & 6 & $\$ 729.00$ & 881 & 250 & -37 \\
\hline CiCi's Pizza & 54 & $\$ 440.10$ & NA & Pizza & NA & $\$ 1,002.00$ & 405 & 41 & -6 \\
\hline Cold Stone Creamery & 53 & $\$ 469.80$ & NA & Snack & NA & $\$ 507.40$ & 916 & 10 & 19 \\
\hline Corner Bakery Cafe & 59 & $\$ 36900$ & $N A$ & Snack & $N A$ & $\$ 221580$ & 83 & 114 & 12 \\
\hline Culver's & 27 & $\$ 1,196.00$ & NA & Burger & 9 & $\$ 2,183.80$ & 552 & 7 & 31 \\
\hline Dairy Queen & 17 & $\$ 3,532.00$ & NA & Snack & 3 & $\$ 783.00$ & 4509 & 2 & -1 \\
\hline Del Taco & 37 & $\$ 700.20$ & NA & Ethnic & 5 & $\$ 1,376.60$ & 247 & 297 & -3 \\
\hline Dickey's Barbecue Pit & 62 & $\$ 358.20$ & NA & Sandwich & NA & $\$ 762.10$ & 499 & 9 & 91 \\
\hline Domino's Pizza & 11 & $\$ 4,800.00$ & 75 & Pizza & 2 & $\$ 900.00$ & 4816 & 384 & 133 \\
\hline Dunkin' Donuts & 7 & $\$ 7,620.00$ & 78 & Snack & 2 & $\$ 903.80$ & 8392 & 39 & 349 \\
\hline Einstein Bros. Bagels & 57 & $\$ 402.00$ & NA & Snack & NA & $\$ 670.00$ & 285 & 315 & -158 \\
\hline El Pollo Loco & 35 & $\$ 753.40$ & NA & Chicken & 8 & $\$ 1,798.00$ & 247 & 186 & 18 \\
\hline Firehouse Subs & 41 & $\$ 648.50$ & NA & Sandwich & 6 & $\$ 726.00$ & 913 & 32 & 95 \\
\hline Five Guys & 26 & $\$ 1,319.50$ & NA & Burger & 8 & $\$ 1,123.00$ & 813 & 402 & 52 \\
\hline Hungry Howie's Pizza & 64 & $\$ 342.50$ & NA & Pizza & NA & $\$ 638.00$ & 531 & 18 & -4 \\
\hline In-N-Out Burger & 45 & $\$ 613.20$ & NA & Burger & 13 & $\$ 1,959.20$ & 0 & 313 & 12 \\
\hline Jack in the Box & 19 & $\$ 3,395.50$ & 72 & Burger & 6 & $\$ 1,510.00$ & 1836 & 413 & -1 \\
\hline Jamba Juice & 50 & $\$ 524.50$ & NA & Snack & 8 & $\$ 641.20$ & 748 & 70 & 12 \\
\hline Jason's Deli & 42 & $\$ 643.60$ & NA & Sandwich & 7 & $\$ 2,664.00$ & 106 & 154 & 7 \\
\hline Jersey Mike's Subs & 40 & $\$ 675.00$ & NA & Sandwich & 5 & $\$ 645.30$ & 1006 & 40 & 189 \\
\hline Jimmy John's Sandwiches & 23 & $\$ 1,978.60$ & NA & Sandwich & 4 & $\$ 877.10$ & 2354 & 51 & 296 \\
\hline KFC & 14 & $\$ 4,328.30$ & 73 & Chicken & 2 & $\$ 1,000.00$ & 4064 & 206 & -121 \\
\hline Krispy Kreme & 36 & $\$ 708.10$ & NA & Snack & 4 & $\$ 1,835.60$ & 181 & 116 & 19 \\
\hline Krystal & 55 & $\$ 420.90$ & NA & Burger & NA & $\$ 1,169.90$ & 125 & 227 & 0 \\
\hline Little Caesars & 18 & $\$ 3,453.20$ & 74 & Pizza & 3 & $\$ 815.00$ & 3626 & 611 & 212 \\
\hline Long John Silver's & 52 & $\$ 512.00$ & NA & Seafood & NA & $\$ 628.00$ & 696 & 41 & -78 \\
\hline Marco's Pizza & 56 & $\$ 417.60$ & NA & Pizza & NA & $\$ 683.50$ & 667 & 0 & 99 \\
\hline McAlister's Deli & 47 & $\$ 547.70$ & NA & Sandwich & 8 & $\$ 1,634.50$ & 318 & 43 & 24 \\
\hline McDonald's & 1 & $\$ 35,800.00$ & 67 & Burger & 1 & $\$ 2,500.00$ & 12899 & 1360 & -91 \\
\hline Moe's Southwest Grill & 43 & $\$ 638.10$ & NA & Ethnic & 6 & $\$ 1,163.00$ & 633 & 5 & 57 \\
\hline Noodles \& Company & 51 & $\$ 517.90$ & NA & Ethnic & NA & $\$ 1,105.00$ & 70 & 422 & 53 \\
\hline Panda Express & 22 & $\$ 2,550.10$ & NA & Ethnic & 3 & $\$ 1,487.00$ & 85 & 1705 & 61 \\
\hline Panera Bread & 10 & $\$ 4.900 .00$ & 80 & Sandwich & 2 & $\$ 2.500 .00$ & 1071 & 901 & 92 \\
\hline
\end{tabular}


Table 1.(cont.) Quick service restaurants (USA, 2015)

\begin{tabular}{|c|c|c|c|c|c|c|c|c|c|}
\hline Company & Rank & Sales & Asci & Segments & Seg_rank & Unit_avg & Fr_u & Co-u & Change \\
\hline Papa John's & 21 & $\$ 2,882.90$ & 78 & Pizza & 4 & $\$ 892.80$ & 2681 & 707 & 48 \\
\hline Papa Murphy's & 30 & $\$ 880.40$ & NA & Pizza & 5 & $\$ 623.50$ & 1369 & 127 & 35 \\
\hline Pizza Hut & 9 & $\$ 5,703.80$ & 78 & Pizza & 1 & $\$ 725.00$ & 7311 & 511 & -109 \\
\hline Pollo Tropical & 60 & $\$ 366.70$ & NA & Chicken & NA & $\$ 2,585.00$ & 35 & 155 & 29 \\
\hline Popeyes Louisiana Kitchen & 20 & $\$ 3,100.00$ & NA & Chicken & 3 & $\$ 1,458.50$ & 2469 & 70 & 160 \\
\hline Pothelly Sandwich Shon & 50 & $\$ 20710$ & $\mathrm{NA}$ & Sonduich & $N A$ & $\$ 106020$ & 24 & $272+>>$ & 14 \\
\hline Potbelly Sandwich Shop & 58 & $\$ 381.40$ & $\mathrm{NA}$ & Salluvicti & INA & $\$ 1,000 . \angle 0$ & $\angle 4$ & $3 / 2$ & 44 \\
\hline Qdoba Mexican Eats & 34 & $\$ 753.70$ & NA & Ethnic & 4 & $\$ 1,169.00$ & 339 & 322 & 23 \\
\hline Quiznos & 63 & $\$ 354.10$ & NA & Sandwich & NA & $\$ 370.00$ & 953 & 4 & -243 \\
\hline Sonic & 13 & $\$ 4,390.00$ & NA & Burger & 4 & $\$ 1,200.00$ & 3139 & 387 & 41 \\
\hline Starbucks & 2 & $\$ 13,300.00$ & 4 & Snack & 1 & $\$ 1,062.20$ & 4962 & 7559 & 303 \\
\hline Steak n Shake & 29 & $\$ 1,032.40$ & NA & Burger & 10 & $\$ 1,866.90$ & 144 & 417 & 16 \\
\hline Subway & 3 & $\$ 11,500.00$ & 77 & Sandwich & 1 & $\$ 424.30$ & 27103 & 0 & 145 \\
\hline Taco Bell & 5 & $\$ 8,820.20$ & 72 & Ethnic & 1 & $\$ 1,460.00$ & 5227 & 894 & 170 \\
\hline Taco John's & 61 & $\$ 358.80$ & NA & Ethnic & $N A$ & $\$ 931.30$ & 378 & 10 & -5 \\
\hline Tim Hortons & 38 & $\$ 695.70$ & NA & Snack & 5 & $\$ 1,143.00$ & 881 & 3 & 0 \\
\hline Wendy's & 6 & $\$ 8,811.90$ & 73 & Burger & 3 & $\$ 1,540.00$ & 5090 & 632 & -58 \\
\hline Whataburger & 24 & $\$ 1,747.00$ & NA & Burger & 7 & $\$ 2,530.00$ & 119 & 672 & 17 \\
\hline White Castle & 39 & $\$ 691.30$ & NA & Burger & 12 & $\$ 1,408.70$ & 0 & 390 & 10 \\
\hline Wingstop & 32 & $\$ 821.20$ & NA & Chicken & 7 & $\$ 1,130.00$ & 826 & 19 & 133 \\
\hline Zaxby's & 25 & $\$ 1,576.40$ & NA & Chicken & 4 & $\$ 2,174.30$ & 602 & 123 & 65 \\
\hline
\end{tabular}

\section{Exploratory data analysis}

3.1. Summarization. The mosaic package provided summary information about sales, unit_avg, and acsi variables.

Table 2. Quick service restaurants sales by segment

\begin{tabular}{|l|c|c|c|c|c|c|c|c|c|}
\hline \multicolumn{1}{|c|}{ Segments } & Min & Q1 & Median & Q3 & Max & Mean & Sd & N & Missing \\
\hline Burger & 420.9 & 840.175 & 1533.25 & 4207.825 & 35800.0 & 5241.793 & 9275.984 & 14 & 0 \\
\hline Chicken & 366.7 & 770.350 & 995.50 & 2719.100 & 6825.9 & 2038.080 & 2099.585 & 10 & 0 \\
\hline Ethnic & 358.8 & 608.050 & 726.95 & 3037.875 & 8820.2 & 2355.025 & 2977.369 & 8 & 0 \\
\hline Pizza & 342.5 & 434.475 & 1881.65 & 3789.900 & 5703.8 & 2365.062 & 2148.799 & 8 & 0 \\
\hline Sandwich & 334.1 & 380.100 & 646.05 & 2368.950 & 11500.0 & 2155.600 & 3289.831 & 12 & 0 \\
\hline Seafood & 512.0 & 516.925 & 521.85 & 526.775 & 531.7 & 521.850 & 13.930 & 2 & 0 \\
\hline Snack & 369.0 & 497.150 & 584.00 & 2120.050 & 13300.0 & 2612.209 & 4180.544 & 11 & 0 \\
\hline
\end{tabular}

Table 3. Quick service restaurants average unit sales by segment

\begin{tabular}{|l|c|c|c|c|c|c|c|c|c|}
\hline \multicolumn{1}{|c|}{ Segments } & Min & Q1 & Median & Q3 & Max & Mean & Sd & N & Missing \\
\hline Burger & 966.5 & 1212.175 & 1459.35 & 1936.125 & 2530.0 & 1610.2929 & 513.5849 & 14 & 0 \\
\hline Chicken & 729.0 & 1188.500 & 1628.25 & 2090.400 & 3977.3 & 1805.4800 & 945.2114 & 10 & 0 \\
\hline Ethnic & 931.3 & 1148.500 & 1272.80 & 1466.750 & 2424.0 & 1389.4875 & 459.1363 & 8 & 0 \\
\hline Pizza & 623.5 & 672.125 & 770.00 & 894.600 & 1002.0 & 784.9750 & 138.5787 & 8 & 0 \\
\hline Sandwich & 370.0 & 680.325 & 819.60 & 1213.375 & 2664.0 & 1119.0417 & 760.1538 & 12 & 0 \\
\hline Seafood & 628.0 & 727.000 & 826.00 & 925.000 & 1024.0 & 826.0000 & 280.0143 & 2 & 0 \\
\hline Snack & 233.3 & 574.300 & 783.00 & 1102.600 & 2215.8 & 954.1273 & 595.9809 & 11 & 0 \\
\hline
\end{tabular}

Table 4. Quick service restaurants ACSI index by segment

\begin{tabular}{|l|c|c|c|c|c|c|c|c|c|}
\hline \multicolumn{1}{|c|}{ Segments } & Min & Q1 & Median & Q3 & Max & Mean & Sd & N & Missing \\
\hline Burger & 67 & 70.75 & 72.0 & 72.25 & 73 & 71.00 & 2.708013 & 4 & 10 \\
\hline Chicken & 73 & 76.25 & 79.5 & 82.75 & 86 & 79.50 & 9.192388 & 2 & 8 \\
\hline Ethnic & 72 & 74.75 & 77.5 & 80.25 & 83 & 77.50 & 7.778175 & 2 & 6 \\
\hline Pizza & 74 & 74.75 & 76.5 & 78.00 & 78 & 76.25 & 2.061553 & 4 & 4 \\
\hline Sandwich & 74 & 75.50 & 77.0 & 78.50 & 80 & 77.00 & 3.000000 & 3 & 9 \\
\hline Seafood & NA & NA & NA & NA & NA & NaN & NA & 0 & 2 \\
\hline Snack & 74 & 75.00 & 76.0 & 77.00 & 78 & 76.00 & 2.828427 & 2 & 9 \\
\hline
\end{tabular}


3.2. Visualization. Dot plots for sales, unit_avg, and acsi are displayed below. For each of these plots, the mean value is displayed in other color. The cowplot
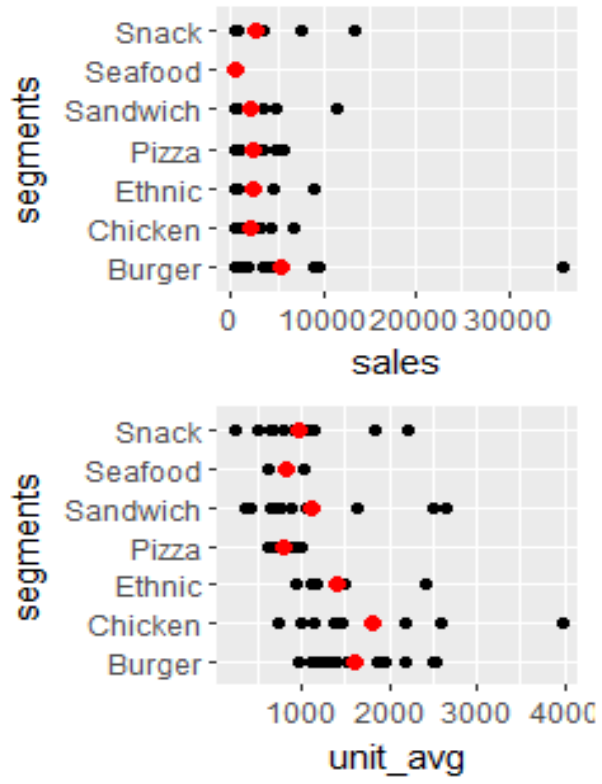

package was utilizied to display multiple ggplot plots together. Multiple plots can also be displayed together by using a function written by Chang (n.d.).
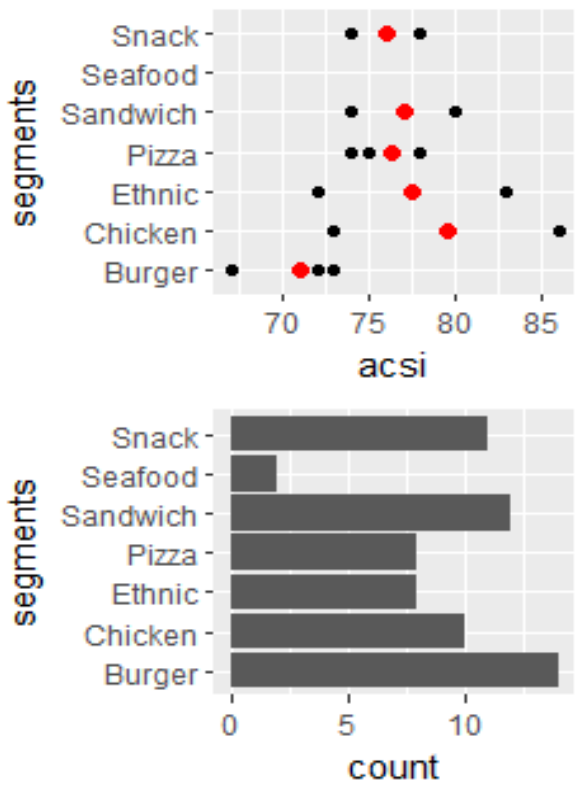

Fig. 2. QSR characteristics by segment

While the leaders in each segment are dispayed in the above figures, two restaurants stand out. McDonald's has the highest level of sales but a low level of ACSI. Chick-fil-A, on the other hand, had a high level of sales per unit and also higher level of ACSI than McDonald's. The number of restaurants by segment, from most to least were burger, sandwich, snack,
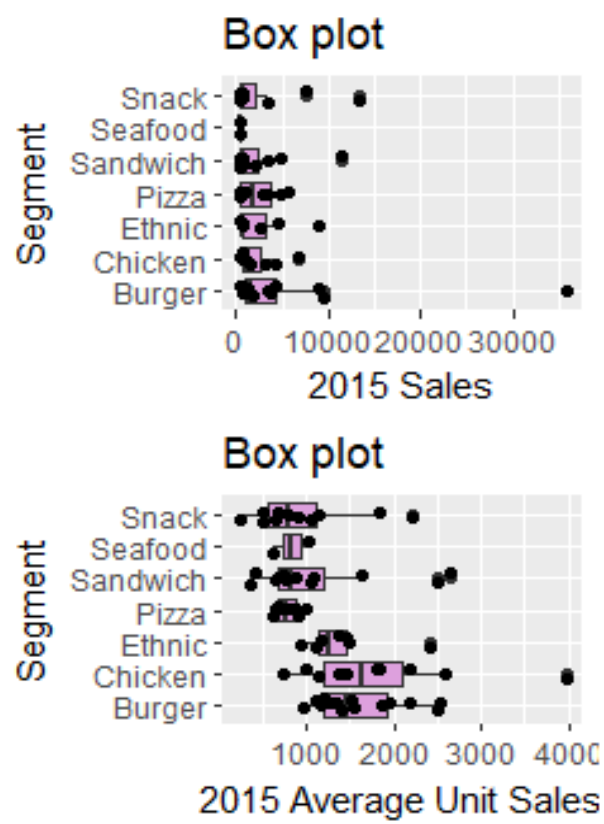

chicken, ethnic, pizza, and seafood restaurants.

\subsection{Box plots and violin plots}

The box plots and violin plots for sales and unit_avg sales are displayed below. The violin plot is a compact version of the density plot that is displayed as a boxplot (Wickhham, 2016).

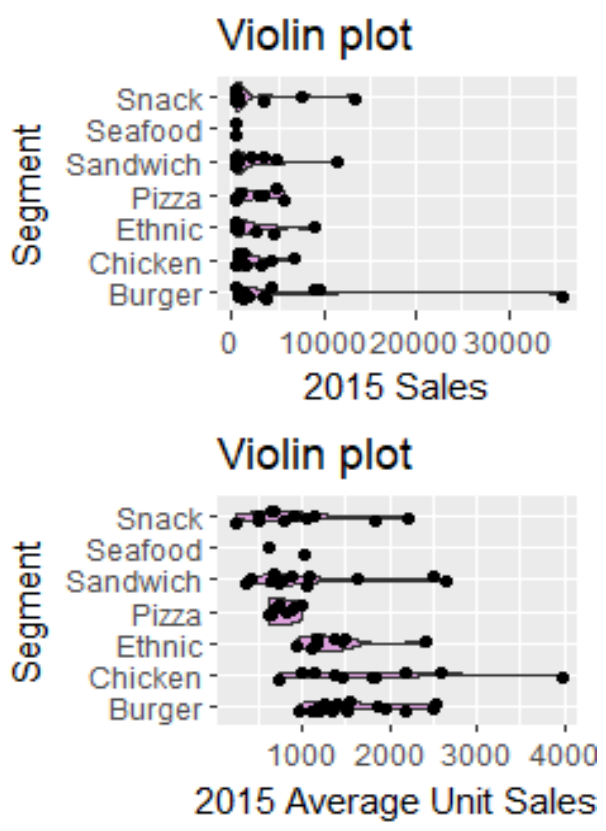

Fig. 3. QSR boxplots and violin plots by segment

3.4. Company sales and average sales per unit versus ACSI

The relationships between company sales (sale) and ACSI (acsi) and also between Average
Sales per Unit (unit avg) and ACSI (acsi) are displayed next. These relationships explore overall patterns at the industry level and address research question \#3. 


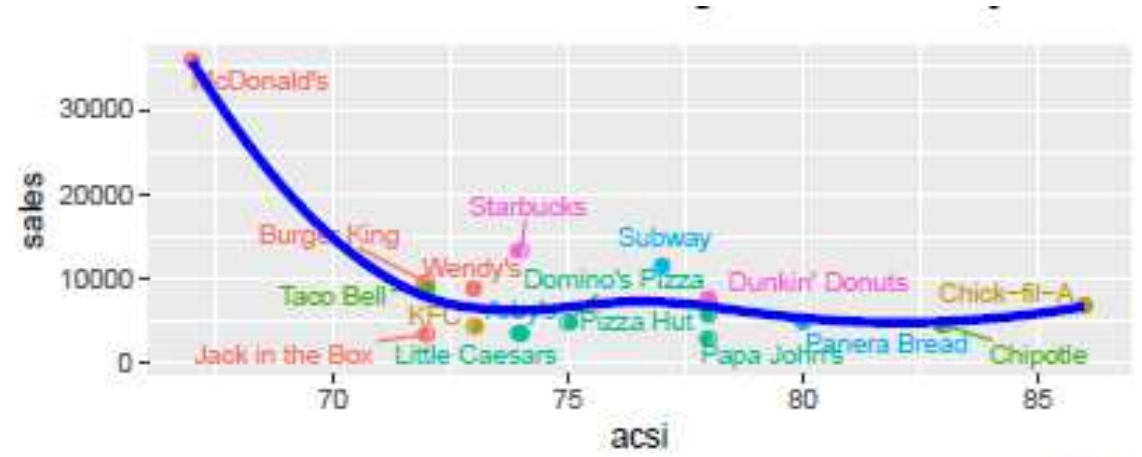

segments

- Burger

- Chicken

- Ethnic

- Pizza

- Sandwich

- Seafood

e Snack

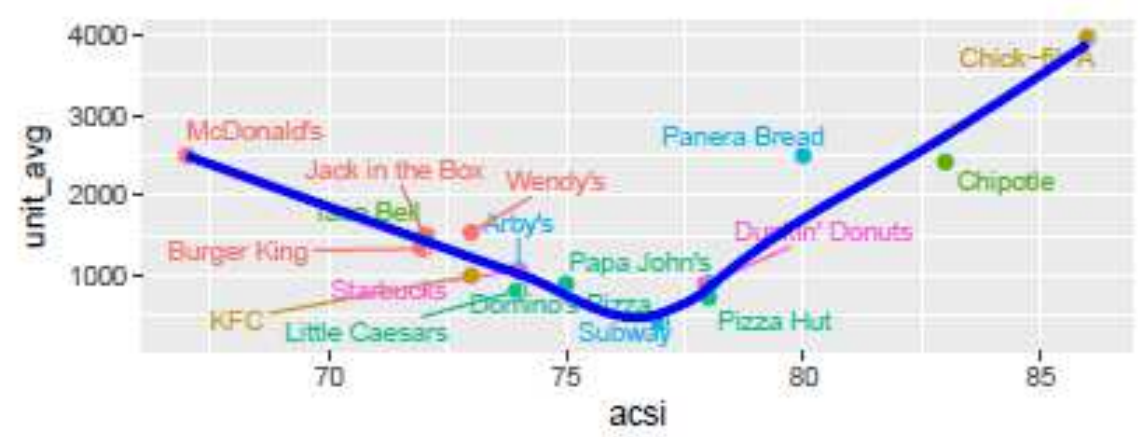

segments

- Burger

- Chicken

- Ethnic

- Pizza

- Sandwich

- Seafood

- Snack

Fig. 4. QSR sales by ACSI and unit average sales by ACSI

3.5. Best-in-segment sales and within-segment The companies with the best-in-segment sales were relationships identified in a plot of the relationship between Sales and ACSI. Next, linear relationships among The data for ACSI were not available for all companies so the mean value was substituted for missing acsi values. companies were displayed within each segment. These relationships address research question $\# 4$ at the segment level.

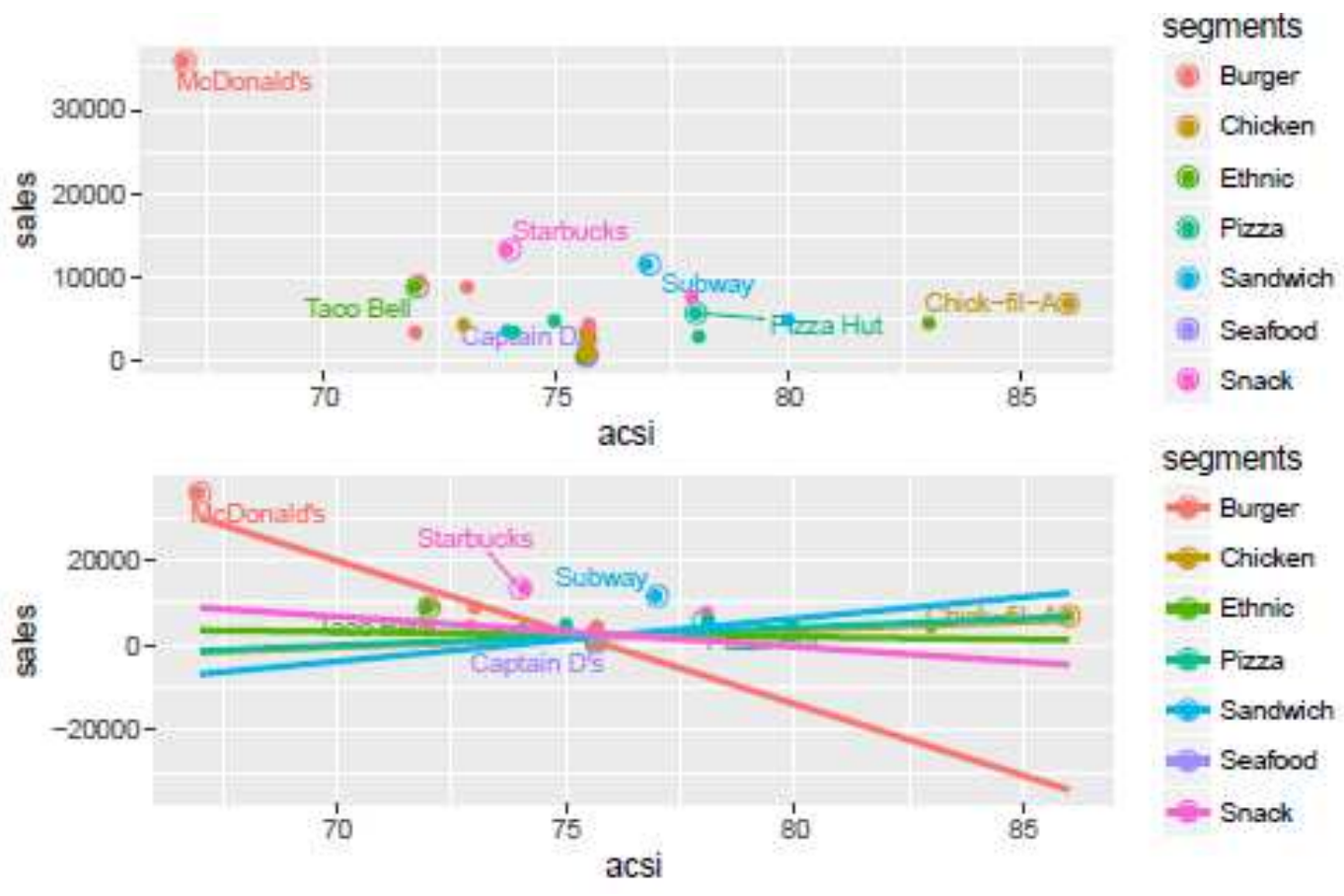

Fig. 5. QSR best-in-segment sales and by segment relationships

3.6. Best-in-segment average sales per unit and within-segment relationships

Next, the best companies in each segment were identified for their Average Sales per Unit (unit_avg). The data for ACSI were not available for all companies so the mean value was substituted for missing acsi values.

The Average Sales per Unit were plotted against ACSI. For each set of plots, the first plot displays only the companies while the second plot displays linear relationships among companies within segments. 


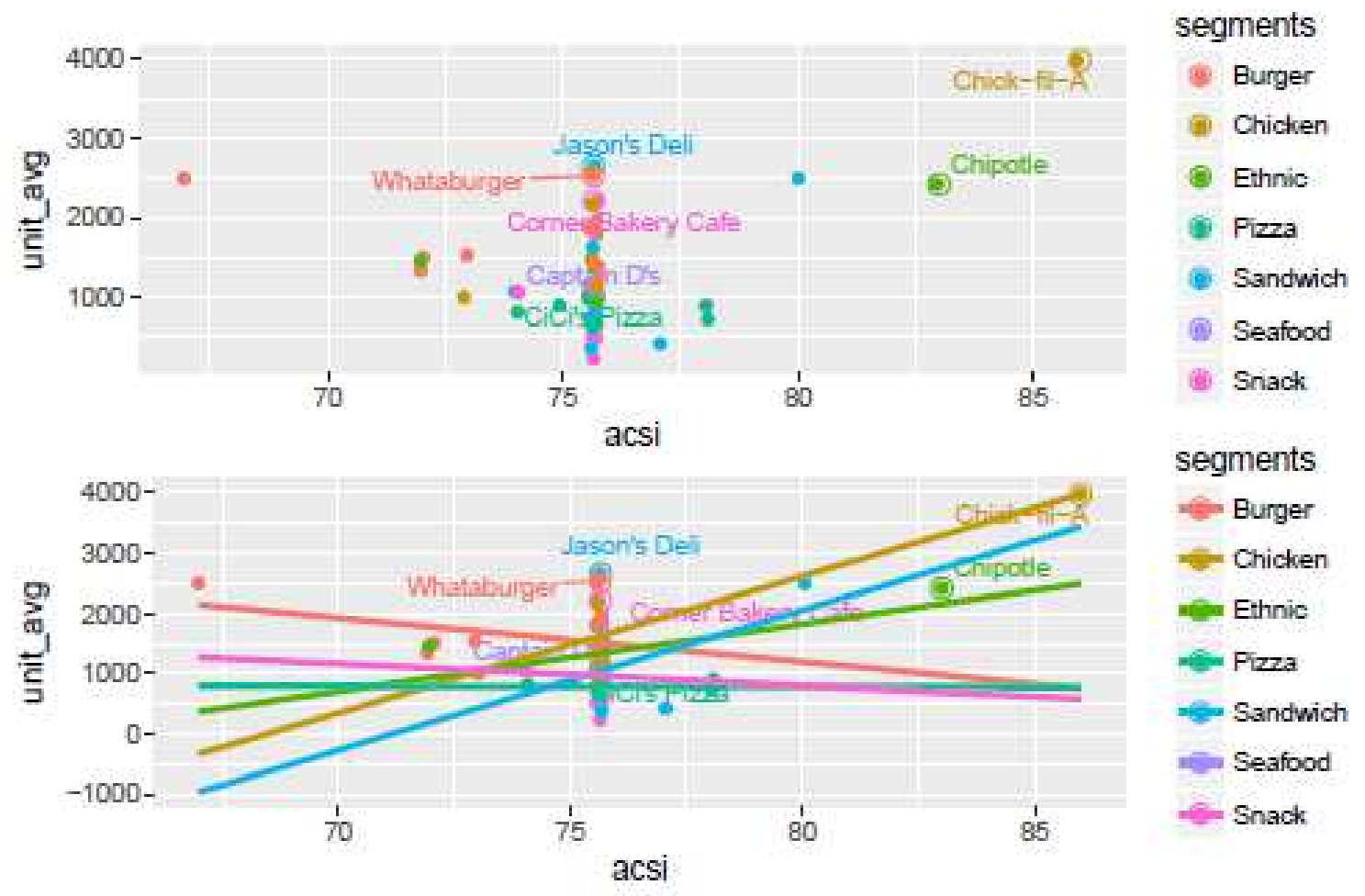

Fig. 6. QSR best-in-segment unit average sales and by segment relationships

\section{Exploratory data analysis}

4.1. Transformation. Table 5 provides summary statistics, Table 6 presents mean values by segment, and Table 7 shows the outlier restaurant which is McDonalds.

The correlations and histograms show a large, positive, and significant relationship between the number of units of a restaurant (units) and its Sales (sales). However, there is no statistically significant relationship betweeen ACSI and Sales of a restaurant. The histograms show skewed distributions for most variables that are largely corrected by $\log$ transformation of these variables.

Table 5. Descriptive Statistics

\begin{tabular}{|c|c|c|c|c|c|c|c|c|}
\hline & Sales & Acsi & Unit_avg & Units & Log_sales & Log_acsi & Log_unit_avg & Log_units \\
\hline Median & 776.10 & 75.65 & 1123.00 & 884.00 & 6.65 & 4.33 & 7.02 & 6.78 \\
\hline Mean & 2879.57 & 75.65 & 1285.70 & 2529.20 & 7.18 & 4.33 & 7.02 & 7.11 \\
\hline SE.mean & 630.58 & 0.28 & 86.74 & 518.42 & 0.14 & 0.00 & 0.07 & 0.14 \\
\hline Cl.mean.0.95 & 1259.73 & 0.57 & 173.29 & 1035.66 & 0.29 & 0.01 & 0.13 & 0.28 \\
\hline Var & 25846197.69 & 5.25 & 489069.37 & 17469238.01 & 1.35 & 0.00 & 0.29 & 1.28 \\
\hline Std. Dev & 5083.92 & 2.29 & 699.33 & 4179.62 & 1.16 & 0.03 & 0.54 & 1.13 \\
\hline Coef.var & 1.77 & 0.03 & 0.54 & 1.65 & 0.16 & 0.01 & 0.08 & 0.16 \\
\hline Skewness & 4.44 & 1.01 & 1.25 & 3.74 & 0.73 & 0.56 & -0.18 & 0.64 \\
\hline Skew.2SE & 7.47 & 1.70 & 2.10 & 6.29 & 1.23 & 0.94 & -0.30 & 1.07 \\
\hline Kurtosis & 24.60 & 8.79 & 1.83 & 17.01 & -0.57 & 8.42 & 0.03 & -0.40 \\
\hline Kurt.2SE & 20.98 & 7.50 & 1.56 & 14.51 & -0.49 & 7.18 & 0.02 & -0.34 \\
\hline Normtest.W & 0.50 & 0.63 & 0.90 & 0.55 & 0.90 & 0.63 & 0.99 & 0.95 \\
\hline Normtest.p & 0.00 & 0.00 & 0.00 & 0.00 & 0.00 & 0.00 & 0.82 & 0.01 \\
\hline
\end{tabular}




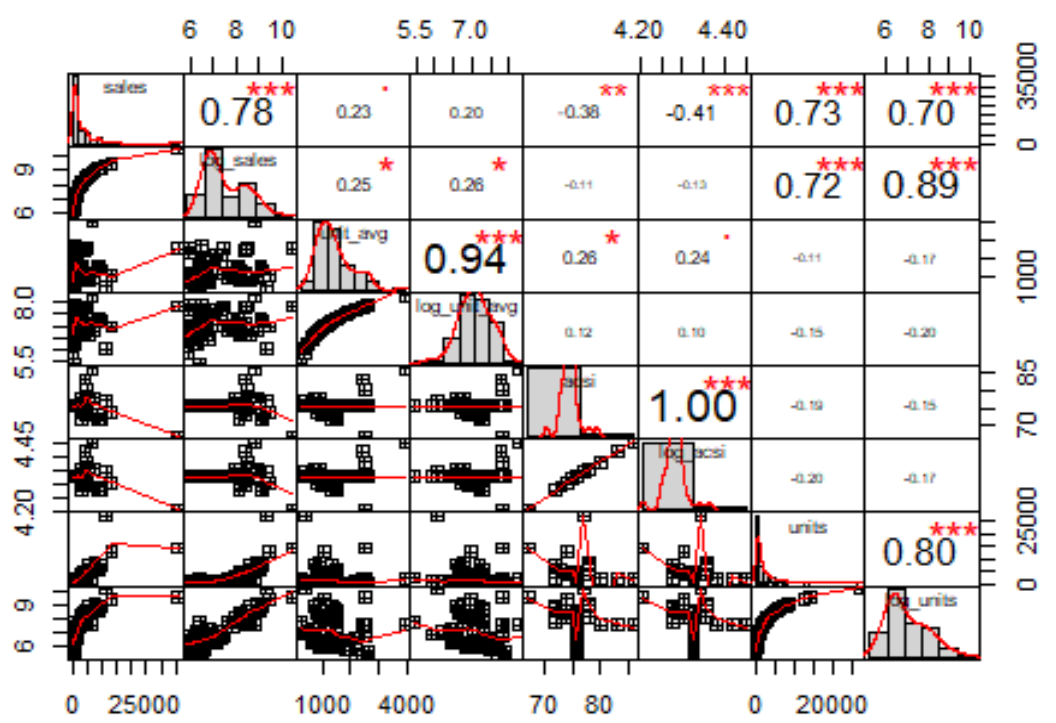

Fig. 7. Scatterplots, histograms, and correlations

Table 6. QSR Mean Values by Segment: Sales (\$ millions), Average Sales per Unit (thousands), and ACSI $(0-100)$

\begin{tabular}{|l|c|c|c|c|}
\hline \multicolumn{1}{|c|}{ Segments } & N & Sales & Unit_avg & Acsi \\
\hline Burger & 14 & 5241.793 & 1610.2929 & 74.31933 \\
\hline Chicken & 10 & 2038.080 & 1805.4800 & 76.41765 \\
\hline Ethnic & 8 & 2355.025 & 1389.4875 & 76.11029 \\
\hline Pizza & 8 & 2365.062 & 784.9750 & 75.94853 \\
\hline Sandwich & 12 & 2155.600 & 1119.0417 & 75.98529 \\
\hline Seafood & 2 & 521.850 & 826.0000 & 75.64706 \\
\hline Snack & 11 & 2612.209 & 954.1273 & 75.71123 \\
\hline
\end{tabular}

Table 7. QSR (Sales > 1500): Sales (millions), Average Sales per Unit (thousands), and ACSI $(0-100)$

\begin{tabular}{|c|c|c|c|}
\hline $\mathrm{n}$ & Sales & Unit_avg & Acsi \\
\hline 1 & 35800 & 2500 & 67 \\
\hline
\end{tabular}

The 2015 U.S. Systemwide Sales (millions) are reported by QSR as follows:

1. McDonald's - $\$ 35,800$;

2. Starbucks $-\$ 13,300$;

3. Subway - $\$ 11,500$;

4. Burger King $-\$ 9,530$.

Here McDonald's stands out for the largest sales of $\$ 35,800$ million, far above the QSR industry average sales of $\$ 2,365$ millions. McDonald's had 2015 ACSI of 67 which is far below the QSR industry average. These figures indicate that McDonald's is an outlier (Table 7). Since OLS regression is sensitive to outliers, McDonald's was removed from the data set before OLS regression analyses were performed.

4.2. Modeling. An Ordinary Least-Squares (OLS) regression model was developed for the overall data and also for each segment. Here the response variable was Sales, and the predictor variables were the total number of units (franchisee and company-owned units) and
ACSI. The following relationships among the response variable and the predictors were hypothesized:

- The higher the number of units, the higher the sales by a company.

- The higher the ACSI, the higher the sales by a company.

4.3. Research question \#3. What factors influence the Sales of a QSR restaurant?

4.4. The overall regression model. The research question \#3 was explored by running an overall regression model with sales as the response variable and acsi and units as predictors.

4.5. General model and its specifications. This study proposes the following general model to describe QSR restaurant's Sales as a function of its rating on ACSI index and its number of Units (restaurants).

Sales $=f($ ACSI,Units $)$.

It is postulated that the Sales of a restaurant are positively related to its ACSI and also to its number of Units.

This general model was specified as an additive model and as a multiplicative model for estimation.

4.6. Model specification \#1: additive model. A linear and additive relationship among the predictor variables is specified as follows:

Sales $=\beta_{0}+\beta_{1} \times A C S I+\beta_{2} \times$ Units $+\varepsilon$.

4.7. Model specification \#2: multiplicative model. A multiplicative model can be transformed to a linear and additive model by taking logs on both sides of the equation.

$$
\log (\text { Sales })=\gamma_{0}+\gamma_{1} \times \log (\text { ACS })+\gamma_{2} \times \log (\text { Units })+\psi
$$

The model specifications in (2) and (3) are linear in parameters that can be estimated by OLS regressions. 
The estimated additive model is given by:

$$
\text { Sales }=-3.676+61 \times A C S I+0.62 \times \text { Units. }
$$

The standardized model is given below:

\#> acsi units

\#> "0.042" "0.821”

The standardized (beta) regression coefficients indicate that the influence of the number of restaurants (units) on Sales (sales) is about 20 times greater than that of ACSI on Sales.

The estimated multiplicative model (converted to the $\log -\log$ scale) is given below:

$$
\log (\text { Sales })=-17+4 \times \log (\text { ACSI })+0.89 \times \log (\text { Units })
$$

Table 8 presents OLS regression and log-log OLS regression results. The OLS regression model has adjusted R-squared of $66.30 \%$ while it is $78.60 \%$ for the log-log OLS regression. Although ACSI is positive in both models, it has a large standard error for OLS regression making it unreliable. The log-log OLS
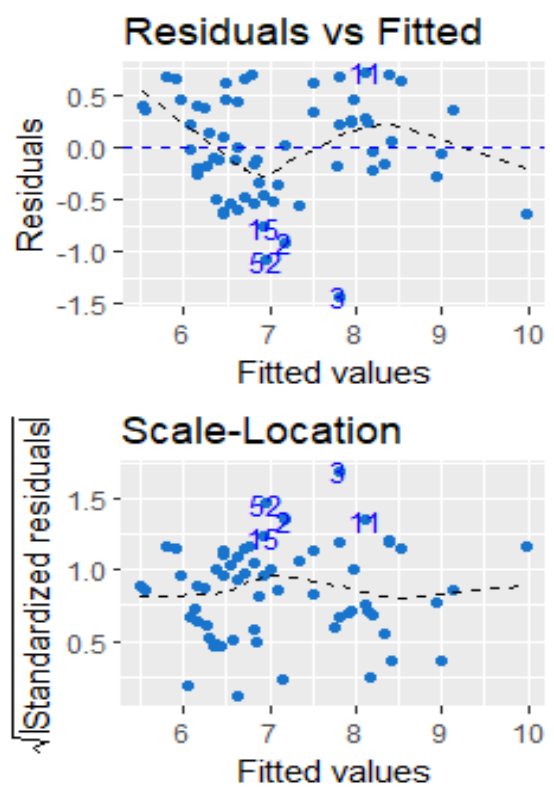

Fig. 8. Diagnostic plots (log-log OLS model)

The global test of the assumptions of the regression model was performed by the gvlma package. The results (Table 9) showed no violations of the assumptions of the regression model. This was also confirmed by four diagnostic plots, namely, Residuals vs Fitted, Normal Q-Q, Scale-Location, and Cook's Distance plots.

Table 9. Global test of log-log OLS regression model's assumptions

\begin{tabular}{|l|c|c|l|}
\hline & Value & P-value & \multicolumn{1}{|c|}{ Decision } \\
\hline Global stat & 4.01 & 0.40 & Assumptions acceptable. \\
\hline Skewness & 2.07 & 0.15 & Assumptions acceptable. \\
\hline Kurtosis & 0.29 & 0.59 & Assumptions acceptable. \\
\hline Link function & 0.95 & 0.33 & Assumptions acceptable. \\
\hline Heteroscedasticity & 0.71 & 0.40 & Assumptions acceptable. \\
\hline
\end{tabular}

regresion model was selected for futher analyses.

Table 8. OLS and log-log OLS models:

\begin{tabular}{|c|c|c|}
\hline & \multicolumn{2}{|c|}{ Dependent variable: } \\
\hline & Sales & Log(Sales) \\
\hline ACSI & $\begin{array}{c}60.607 \\
(106.705)\end{array}$ & \\
\hline Units & $\begin{array}{l}0.618^{\star \star \star} \\
(0.055)\end{array}$ & \\
\hline $\log (A C S I)$ & & $\begin{array}{l}4.048 \\
(2.457)\end{array}$ \\
\hline Log(Units) & & $\begin{array}{l}0.887^{\star \star \star} \\
(0.058)\end{array}$ \\
\hline Constant & $\begin{array}{l}-3,676.455 \\
(8,093.578)\end{array}$ & $\begin{array}{l}-16.653 \\
(10.657)\end{array}$ \\
\hline Observations & 64 & 64 \\
\hline $\mathrm{R}^{2}$ & 0.674 & 0.793 \\
\hline Adjusted R2 & 0.663 & 0.786 \\
\hline Residual Std. Error $(\mathrm{df}=61)$ & $1,719.808$ & 0.507 \\
\hline F Statistic ( $\mathrm{df}=2 ; 61)$ & $63.063^{* \star \star}$ & $116.603^{* \star \star}$ \\
\hline
\end{tabular}
2015 dataset

Note: ${ }^{*} \mathrm{p}<0.1 ; * * \mathrm{p}<0.05 ; * * * \mathrm{p}<0.01$..

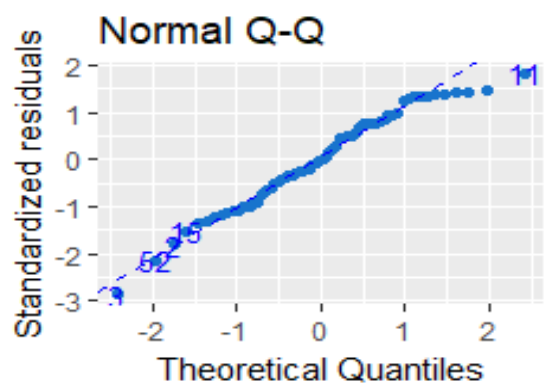

Cook's distance

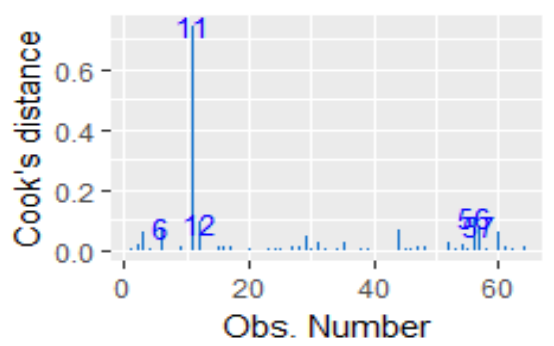

Although Chick-fil-A (number 11) stood out, no restaurant had significant influence on regression coefficients as measured by Cook's distance larger than 4. Recall that McDonald's was already removed from this analysis.

Answer \#3. The overall model of the relationship between Sales and ACSI Units was statistically significant with an adjusted R squared value of 0.79 for the log-log model. There was a positive relationship between Sales and ACSI and also between Sales and the number of units of a restaurant. However, the relationship between Sales and ACSI was not significant.

Next, research question \#4 was explored by running this regression model at the segment level. 
Table 10. Quick service restaurants $($ segment $=$ sandwich $)$

\begin{tabular}{|c|c|c|c|c|c|c|c|c|}
\hline Company & Sales & Acsi & Unit_avg & Units & Log_sales & Log_acsi & Log_unit_avg & Log_units \\
\hline Arby's & 3540.0 & 74.00 & 1073.0 & 3214 & 8.17 & 4.30 & 6.98 & 8.08 \\
\hline $\begin{array}{l}\text { Charleys Philly } \\
\text { Steaks }\end{array}$ & 334.1 & 75.65 & 692.0 & 551 & 5.81 & 4.33 & 6.54 & 6.31 \\
\hline $\begin{array}{l}\text { Dickey's } \\
\text { Barbecue Pit }\end{array}$ & 358.2 & 75.65 & 762.1 & 508 & 5.88 & 4.33 & 6.64 & 6.23 \\
\hline Firehouse Subs & 648.5 & 75.65 & 726.0 & 945 & 6.47 & 4.33 & 6.59 & 6.85 \\
\hline Jason's Deli & 643.6 & 75.65 & 2664.0 & 260 & 6.47 & 4.33 & 7.89 & 5.56 \\
\hline $\begin{array}{l}\text { Jersey Mike's } \\
\text { Subs }\end{array}$ & 675.0 & 75.65 & 645.3 & 1046 & 6.51 & 4.33 & 6.47 & 6.95 \\
\hline $\begin{array}{l}\text { Jimmy John's } \\
\text { Sandwiches }\end{array}$ & 1978.6 & 75.65 & 877.1 & 2405 & 7.59 & 4.33 & 6.78 & 7.79 \\
\hline McAlister's Deli & 547.7 & 75.65 & 1634.5 & 361 & 6.31 & 4.33 & 7.40 & 5.89 \\
\hline Panera Bread & 4900.0 & 80.00 & 2500.0 & 1972 & 8.50 & 4.38 & 7.82 & 7.59 \\
\hline $\begin{array}{l}\text { Potbelly } \\
\text { Sandwich Shop }\end{array}$ & 387.4 & 75.65 & 1060.2 & 396 & 5.96 & 4.33 & 6.97 & 5.98 \\
\hline Quiznos & 354.1 & 75.65 & 370.0 & 957 & 5.87 & 4.33 & 5.91 & 6.86 \\
\hline Subway & 11500.0 & 77.00 & 424.3 & 27103 & 9.35 & 4.34 & 6.05 & 10.21 \\
\hline
\end{tabular}

Table 11. Quick service restaurants $($ segment $=$ chicken)

\begin{tabular}{|c|c|c|c|c|c|c|c|c|}
\hline Company & Sales & Acsi & Unit_avg & Units & Log_sales & Log_acsi & Log_unit_avg & Log_units \\
\hline Bojangles' & 1153.0 & 75.65 & 1838.7 & 659 & 7.05 & 4.33 & 7.52 & 6.49 \\
\hline Boston Market & 617.9 & 75.65 & 1364.0 & 458 & 6.43 & 4.33 & 7.22 & 6.13 \\
\hline Chick-fil-A & 6825.9 & 86.00 & 3977.3 & 1983 & 8.83 & 4.45 & 8.29 & 7.59 \\
\hline $\begin{array}{l}\text { Church's } \\
\text { Chicken }\end{array}$ & 838.0 & 75.65 & 729.0 & 1131 & 6.73 & 4.33 & 6.59 & 7.03 \\
\hline El Pollo Loco & 753.4 & 75.65 & 1798.0 & 433 & 6.62 & 4.33 & 7.49 & 6.07 \\
\hline KFC & 4328.3 & 73.00 & 1000.0 & 4270 & 8.37 & 4.29 & 6.91 & 8.36 \\
\hline Pollo Tropical & 366.7 & 75.65 & 2585.0 & 190 & 5.90 & 4.33 & 7.86 & 5.25 \\
\hline $\begin{array}{l}\text { Popeyes } \\
\text { Louisiana } \\
\text { Kitchen }\end{array}$ & 3100.0 & 75.65 & 1458.5 & 2539 & 8.04 & 4.33 & 7.29 & 7.84 \\
\hline Wingstop & 821.2 & 75.65 & 1130.0 & 845 & 6.71 & 4.33 & 7.03 & 6.74 \\
\hline Zaxby's & 1576.4 & 75.65 & 2174.3 & 725 & 7.36 & 4.33 & 7.68 & 6.59 \\
\hline
\end{tabular}

4.8. Nested data by segment. The data were nested by segment to facilitate modeling by segments. Tables 10-15 present segment level data.

4.9. Research question \#4. What factors influence the Sales of a QSR restaurant within each segment? This question was explored next at the segment level.

4.10. Regression models by segments. The nested data were input to a function, segment_model, to obtain OLS regression models for each segment. These regression models were then stored in by_segment database and displayed below.

\#> \# A tibble: 7 x 3

$\#>$ segments data model

\# $>\quad<$ chr $>\quad<$ list $><$ list $>$

\#> 1 Sandwich $<$ tibble $[12 \times 9]><$ S3: $1 \mathrm{~m}>$ \#>2 Snack <tibble [ $\left[\begin{array}{lll}1 & \text { x } & 9\end{array}\right]><$ S3: $1 \mathrm{~m}>$

Table 12. Quick service restaurants $($ segment $=$ burger $)$

\begin{tabular}{|l|c|c|c|c|c|c|c|c|}
\hline \multicolumn{1}{|c|}{ Company } & Sales & Acsi & Unit_avg & Units & Log_sales & Log_acsi & Log_unit_avg & Log_units \\
\hline Burger King & 9530.0 & 72.00 & 1337.4 & 7126 & 9.16 & 4.28 & 7.20 & 8.87 \\
\hline $\begin{array}{l}\text { Carl's } \\
\text { Jr./Hardee's }\end{array}$ & 3661.3 & 75.65 & 1248.7 & 2958 & 8.21 & 4.33 & 7.13 & 7.99 \\
\hline Checkers/Rally's & 776.1 & 75.65 & 966.5 & 829 & 6.65 & 4.33 & 6.87 & 6.72 \\
\hline Culver's & 1196.0 & 75.65 & 2183.8 & 559 & 7.09 & 4.33 & 7.69 & 6.33 \\
\hline Five Guys & 1319.5 & 75.65 & 1123.0 & 1215 & 7.19 & 4.33 & 7.02 & 7.10 \\
\hline
\end{tabular}


Table 12. (cont.) Quick service restaurants (segment $=$ burger $)$

\begin{tabular}{|c|c|c|c|c|c|c|c|c|}
\hline Company & Sales & Acsi & Unit_avg & Units & Log_sales & Log_acsi & Log_unit_avg & Log_units \\
\hline In-N-Out Burger & 613.2 & 75.65 & 1959.2 & 313 & 6.42 & 4.33 & 7.58 & 5.75 \\
\hline Jack in the Box & 3395.5 & 72.00 & 1510.0 & 2249 & 8.13 & 4.28 & 7.32 & 7.72 \\
\hline Krystal & 420.9 & 75.65 & 1169.9 & 352 & 6.04 & 4.33 & 7.06 & 5.86 \\
\hline Sonic & 4390.0 & 75.65 & 1200.0 & 3526 & 8.39 & 4.33 & 7.09 & 8.17 \\
\hline Steak $n$ Shake & 1032.4 & 75.65 & 1866.9 & 561 & 6.94 & 4.33 & 7.53 & 6.33 \\
\hline Wendy's & 8811.9 & 73.00 & 1540.0 & 5722 & 9.08 & 4.29 & 7.34 & 8.65 \\
\hline Whataburger & 1747.0 & 75.65 & 2530.0 & 791 & 7.47 & 4.33 & 7.84 & 6.67 \\
\hline White Castle & 691.3 & 75.65 & 1408.7 & 390 & 6.54 & 4.33 & 7.25 & 5.97 \\
\hline
\end{tabular}

Table 13. Quick service restaurants $($ segment $=$ seafood $)$

\begin{tabular}{|l|c|c|c|c|c|c|c|c|}
\hline \multicolumn{1}{|c|}{ Company } & Sales & Acsi & Unit_avg & Units & Log_sales & Log_acsi & Log_unit_avg & Log_units \\
\hline Captain D's & 531.7 & 75.65 & 1024 & 510 & 6.28 & 4.33 & 6.93 & 6.23 \\
\hline $\begin{array}{l}\text { Long John } \\
\text { Silver's }\end{array}$ & 512.0 & 75.65 & 628 & 737 & 6.24 & 4.33 & 6.44 & 6.60 \\
\hline
\end{tabular}

Table 14. Quick service restaurants $($ segment $=$ ethnic)

\begin{tabular}{|c|c|c|c|c|c|c|c|c|}
\hline Company & Sales & Acsi & Unit_avg & Units & Log_sales & Log_acsi & Log_unit_avg & Log_units \\
\hline Chipotle & 4501.2 & 83.00 & 2424.0 & 1971 & 8.41 & 4.42 & 7.79 & 7.59 \\
\hline Del Taco & 700.2 & 75.65 & 1376.6 & 544 & 6.55 & 4.33 & 7.23 & 6.30 \\
\hline $\begin{array}{l}\text { Moe's } \\
\text { Southwest Grill }\end{array}$ & 638.1 & 75.65 & 1163.0 & 638 & 6.46 & 4.33 & 7.06 & 6.46 \\
\hline $\begin{array}{l}\text { Noodles \& } \\
\text { Company }\end{array}$ & 517.9 & 75.65 & 1105.0 & 492 & 6.25 & 4.33 & 7.01 & 6.20 \\
\hline Panda Express & 2550.1 & 75.65 & 1487.0 & 1790 & 7.84 & 4.33 & 7.30 & 7.49 \\
\hline $\begin{array}{l}\text { Qdoba Mexican } \\
\text { Eats }\end{array}$ & 753.7 & 75.65 & 1169.0 & 661 & 6.62 & 4.33 & 7.06 & 6.49 \\
\hline Taco Bell & 8820.2 & 72.00 & 1460.0 & 6121 & 9.08 & 4.28 & 7.29 & 8.72 \\
\hline Taco John's & 358.8 & 75.65 & 931.3 & 388 & 5.88 & 4.33 & 6.84 & 5.96 \\
\hline
\end{tabular}

Table 15. Quick service restaurants $($ segment $=$ pizza)

\begin{tabular}{|l|c|c|c|c|c|c|c|c|}
\hline \multicolumn{1}{|c|}{ Company } & Sales & Acsi & Unit_avg & Units & Log_sales & Log_acsi & Log_unit_avg & Log_units \\
\hline CiCi's Pizza & 440.1 & 75.65 & 1002.0 & 446 & 725.0 & 4.33 & 6.91 & 6.10 \\
\hline Domino's Pizza & 4800.0 & 75.00 & 900.0 & 5200 & 8.48 & 4.32 & 6.80 & 8.56 \\
\hline $\begin{array}{l}\text { Hungry Howie's } \\
\text { Pizza }\end{array}$ & 342.5 & 75.65 & 638.0 & 549 & 5.84 & 4.33 & 6.46 & 6.31 \\
\hline Little Caesars & 3453.2 & 74.00 & 815.0 & 4237 & 8.15 & 4.30 & 6.70 & 8.35 \\
\hline Marco's Pizza & 417.6 & 75.65 & 683.5 & 667 & 6.03 & 4.33 & 6.53 & 6.50 \\
\hline \multicolumn{7}{|l|}{} \\
\hline Papa John's & 2882.9 & 78.00 & 892.8 & 3388 & 7.97 & 4.36 & 6.79 & 8.13 \\
\hline Papa Murphy's & 880.4 & 75.65 & 623.5 & 1496 & 6.78 & 4.33 & 6.44 & 7.31 \\
\hline Pizza Hut & 5703.8 & 78.00 & 725.0 & 7822 & 8.65 & 4.36 & 6.59 & 8.96 \\
\hline
\end{tabular}

Table 16. Quality measures of regression models

\begin{tabular}{|l|c|c|c|c|c|c|c|c|c|c|c|}
\hline \multicolumn{1}{|c|}{ Segments } & R.squared & Adj.r.squared & Sigma & Statistic & P.value & Df & LogLik & AIC & BIC & Deviance & Df.residual \\
\hline Sandwich & 0.82 & 0.78 & 0.56 & 20.44 & 0 & 3 & 24.72 & 24.72 & 26.66 & 2.83 & 9 \\
\hline Snack & 0.77 & 0.71 & 0.69 & 13.07 & 0 & 3 & 27.47 & 27.47 & 29.06 & 3.78 & 8 \\
\hline Chicken & 0.90 & 0.87 & 0.33 & 32.06 & 0 & 3 & 10.77 & 10.77 & 11.98 & 0.77 & 7 \\
\hline Burger & 0.94 & 0.93 & 0.27 & 81.74 & 0 & 3 & 7.26 & 7.26 & 9.51 & 0.72 & 10 \\
\hline Seafood & 1.00 & $\mathrm{NaN}$ & $\mathrm{NaN}$ & $\mathrm{NaN}$ & $\mathrm{NaN}$ & 2 & $\operatorname{Inf}$ & $-\operatorname{Inf}$ & $-\operatorname{Inf}$ & 0.00 & 0 \\
\hline \multicolumn{8}{|c|}{} \\
\hline Ethnic & 0.99 & 0.99 & 0.10 & 464.53 & 0 & 3 & 8.95 & -9.89 & -9.58 & 0.05 & 5 \\
\hline Pizza & 0.97 & 0.96 & 0.22 & 96.90 & 0 & 3 & 2.56 & 2.89 & 3.20 & 0.25 & 5 \\
\hline
\end{tabular}


\#> 3 Chicken $<$ tibble $[10 \times 9]><$ S3: $1 \mathrm{~m}>$

$\#>4$ Burger $<$ tibble $[13 \times 9]><$ S3: $1 \mathrm{~m}>$

$\#>5$ Seafood $<$ tibble $[2 \times 9]><$ S3: $1 \mathrm{~m}>$

\#> 6 Ethnic <tibble $[8 \times 9]><$ S3: $1 \mathrm{~m}>$

\#> 7 Pizza $<$ tibble $[8 \times 9]><$ S3: $1 \mathrm{~m}>$

4.11. Displaying models with the broom package. The glance option in the broom package in $R$, facilitates displaying the quality measures of multiple models. The list columns are dropped $($. drop $=$ TRUE $)$ to facilitate display of important results.

Table 16 presents the model quality measures for each segment while Table 17 presents the regression coefficients for each segment.

Answer \#4. The models depicting the relationship between Sales and ACSI at the segment level were statistically significant and had high adjusted R squared values (71\% - 90\%) implying good models for prediction. The seafood segment was excluded due to limited dataset of only two restaurants.

The tidy option in the broom package facilitates displaying the regression coefficients of multiple models.

The relationship between Sales and ACSI varied by segment:
- It was positive and statistically significant for chicken and ethnic restaurants.

- It was negative and not statistically significant for sanck, burgers, and pizza restaurants.

- The seafood segment was excluded due to limited dataset of only two restaurants.

\section{Limitations}

Like most studies, this study had some limitations as well:

- The main limitation was a small sample of 65 restaurants that were divided into seven segments. Some segments had too few restaurants to develop significant regression models. For example, the seafood segment had only two restaurants so a regression analysis could not be performed for this segment. Therefore, for segments with very few restaurants, the earlier visual models were quite useful.

- In addition, the ACSI score was not available for all resaturants so the mean value for this variable was substitued for the missing values.

- The factors influencing profit or customer satisfaction of a restaurant were not investigated.

Table 17. Coefficients of regression models

\begin{tabular}{|c|c|c|c|c|c|}
\hline Segments & Term & Estimate & Std.Error & Statistic & P.Value \\
\hline Sandwich & (Intercept) & -62.20 & 40.98 & -1.52 & 0.16 \\
\hline Sandwich & $\log ($ acsi) & 14.71 & 9.52 & 1.55 & 0.16 \\
\hline Sandwich & $\log$ (units) & 0.77 & 0.14 & 5.62 & 0.00 \\
\hline Snack & (Intercept) & 4.24 & 79.07 & 0.05 & 0.96 \\
\hline Snack & $\log ($ acsi) & -0.78 & 18.28 & -0.04 & 0.97 \\
\hline Snack & $\log$ (units) & 0.84 & 0.17 & 5.11 & 0.00 \\
\hline Chicken & (Intercept) & -31.54 & 11.11 & -2.84 & 0.03 \\
\hline Chicken & $\log ($ acsi) & 7.61 & 2.58 & 2.95 & 0.02 \\
\hline Chicken & $\log$ (units) & 0.84 & 0.12 & 7.01 & 0.00 \\
\hline Burger & (Intercept) & 21.30 & 23.27 & 0.92 & 0.38 \\
\hline Burger & $\log ($ acsi) & -4.61 & 5.28 & -0.87 & 0.40 \\
\hline Burger & $\log$ (units) & 0.86 & 0.10 & 8.79 & 0.00 \\
\hline Seafood & (Intercept) & 6.92 & $\mathrm{NaN}$ & $\mathrm{NaN}$ & $\mathrm{NaN}$ \\
\hline Seafood & log(units) & -0.10 & $\mathrm{NaN}$ & $\mathrm{NaN}$ & $\mathrm{NaN}$ \\
\hline Ethnic & (Intercept) & -23.02 & 4.23 & -5.45 & 0.00 \\
\hline Ethnic & $\log ($ acsi) & 5.01 & 0.97 & 5.18 & 0.00 \\
\hline Ethnic & log(units) & 1.23 & 0.04 & 30.41 & 0.00 \\
\hline Pizza & (Intercept) & 4.11 & 20.51 & 0.20 & 0.85 \\
\hline Pizza & $\log (\mathrm{acsi})$ & -1.10 & 4.77 & -0.23 & 0.83 \\
\hline Pizza & log(units) & 1.05 & 0.08 & 13.54 & 0.00 \\
\hline
\end{tabular}

\section{Conclusion and recommendations for future research}

This study utilized the open source $\mathrm{R}$ language and environment and the tidyverse package to analyze the role of American Customer Satisfaction on the Sales of Quick Service Restaurants in the US. The answers for the four research questions in this study are summarized below: 
1. There were seven QSR segments: burger, chicken, sandwich, pizza, seafood, ethnic, and snack.

2. The leaders in each QSR segment were listed by seg_rank: McDonald's (burger), Chick-fil-A (chicken), Subway (sandwich), Pizza Hut (pizza), Captain D's (seafood), Taco Bell (ethnic), and Starbucks (snack).

3. This study showed a positive relationship between Sales, the number of restaurants, and American Customer Satisfaction (ACSI) with a QSR restaurant. While the overall model was good and statistically significant, the regression coefficient for the number of restaurant units was statistically significant, that for ACSI was not statistically significant.

4. The relationship between Sales and American Customer Satisfaction with a QSR varied by QSR segment. It was statistically significant and positive for chicken and ethnic restaurants and not significant for other segments. The relationship between Sales and the number of restaurant units was positive and statistically significant for all segments.

In addition, McDonald's and Chick-fil-A stood out from other QSR restaurants. McDonald's had the largest sales volume but the lowest customer satisfaction level, while Chick-fil-A had the highest customer satisfaction level and highest average sales per unit. It should also be noted that, unlike other QSR in the industry, Chick-fil-A is closed on Sundays. Both of these restaurants were the leaders in their own segments.

Studies that can be reproduced and replicated by the readers help in accumulating scientific knowledge in a discipline. For this purpose, it is imperative to utilize open source software and make both the code and the data publicly available.

Future researchers should reproduce this study with the $\mathrm{R}$ code and data provided here and replicate these findings with data for other years. They should also utilize a larger sample size and larger samples per segment for their model building efforts.

They should also improve upon the linear model used here by exploring non-linear models and by utilizing more comprehensive data about characteristics of various restaurants. They should also replicate these findings for data from other countries. They could also explore factors that influence a company's profit and customer satisfaction and provide guidelines to managers.

\section{References}

1. ACSI LLC (2017). American Customer Satisfaction Index Benchmarks By Industry: Limited-Service Restaurants. Retrieved from http://www.theacsi.org/index.php?option=com content\&view=article\&id=147\&catid=\&Itemid=212\&i/

2. Chang, Winston. (n.d.). Multiple graphs on one page (ggplot2). In Cookbook for R. Retrieved from http://www.cookbook-r.com/Graphs/Multiple_graphs_on_one_page_(ggplot2)/

3. Held, Fabian P. (2017). Introduction to the Tidyverse. Retrieved from http://www.fabianheld.com/r-tidyverse/ (accessed on June 23, 2017).

4. Levy, Michael. (2016). Tidyverse Tutorial. Retrieved from https://www.r-bloggers.com/tidyverse-tutorial/ (accessed on October 17, 2016)

5. QSR, Inc. (2016). The QSR 50: An inside look at the top 50 brands in quick service and fast casual. Retrieved from https://www.qsrmagazine.com/reports/qsr50-2016-top-50-chart (accessed on August, 2016)

6. R \& Data Science. Retrieved from http://www.sthda.com/english/wiki/ggplot2-dot-plot-quick-start-guide-rsoftware-and-data-visualization

7. R Views (2017). What is the tidyverse? Retrieved from https://www.r-bloggers.com/what-is-the-tidyverse/ (accessed on June, 2017).

8. The R Foundation (n.d.). The R Project for Statistical Computing. Retrieved from https://www.r-project.org/

9. The tidyverse: dplyr, ggplot2, and friends. (n.d). Retrieved from https://monashbioinformaticsplatform.github.io/

10. Tibble Data Format in R: Best and Modern Way to Work with Your Data. Retrieved from http://www.sthda.com/english/wiki/tibble-data-format-in-r-best-and-modern-way-to-work-with-your-data

11. Tidyverse (n.d.) Retrieved from http://tidyverse.tidyverse.org/

12. Tidyverse packages (n.d.). Retrieved from https://www.tidyverse.org/packages/

13. Wickham, Hadley, \& Grolemund, Garrett. (2017). R for Data Science: Import, Tidy, Transform, Visualize, and Model Data. O'Reilly. Retrieved from http://r4ds.had.co.nz/

14. Wickham, Hadley. (2016). Tidyverse 1.0.0. Retrieved from https://blog.rstudio.com/2016/09/15/tidyverse-1-0-0/ (accessed on September 5, 2016).

15. Wickham, Hadley. (2017). The Tidy Tools Manifesto. Retrieved from https://mran.microsoft.com/web/packages/tidyverse/vignettes/manifesto.html (accessed on January 27, 2017).

16. Wickhham, Hadley. (2016). Ggplot2. Second edition. Springer.

17. Wilke, C. O. (2016). Introduction to cowplot. Retrieved from https://cran.r-project.org/web/packages/ 


\section{Appendix ( $\mathrm{R}$ Code)}

knitr: :opts_chunk\$set $($ echo $=$ FALSE, comment $=" \#>"$, collapse $=$ TRUE, message $=$ FALSE, warning $=$ FALSE, scipen $=5$, digits $=3$ )

\# install.packages("tidyverse")

library(tidyverse)

library (modelr)

library(ggrepel)

\# read data file

qsr65 <- read_csv("qsr65_v1.csv")

\# print data table

library(kableExtra)

knitr::kable(qsr65, format = "latex", digits $=2$, caption = 'Quick Service Restaurants (USA, 2015)', booktabs $=$ T) $\%>\%$

\# kable_styling(Latex_options = c("striped", "scale_down", font_size = 7))

kable_styling(bootstrap_options = "striped", font_size = 7)

\# Helper function by Wickham \& Grolemund (2016, p. 434). Set number of digits to reasonable

\# accuracy and make it easier to read numbers by inserting commas.

comma <- function $(x)$ format $(x$, digits $=2$, big.mark $=$ ", ")

library(tidyverse)

library (modelr)

\# replace \$ and commas with blanks "" and change character to numeric

qsr65\$sales <- as.numeric(gsub("[\\\$,]", " ", qsr65\$sales))

qsr65\$unit_avg<- as.numeric(gsub("[\\,]", "", qsr65\$unit_avg))

library (mosaic)

sales_seg <- favstats (sales segments, data= qsr65)

knitr::kable(sales_seg, caption = 'Quick Service Restaurants Sales by Segment') \%>\%

kable_styling(bootstrap_options = "striped", font_size = 7)

unit_avg_seg <- favstats(unit_avg segments, data=qsr65)

knitr::kable(unit_avg_seg, caption = 'Quick Service Restaurants Average Unit Sales by Segment') $\%>\%$

kable_styling(bootstrap_options = "striped", font_size = 7)

acsi_seg <- favstats(acsi segments, data=qsr65)

knitr::kable(acsi_seg, caption = 'Quick Service Restaurants ACSI Index by Segment') \%>\%

kable_styling(bootstrap_options = "striped", font_size $=7$ )

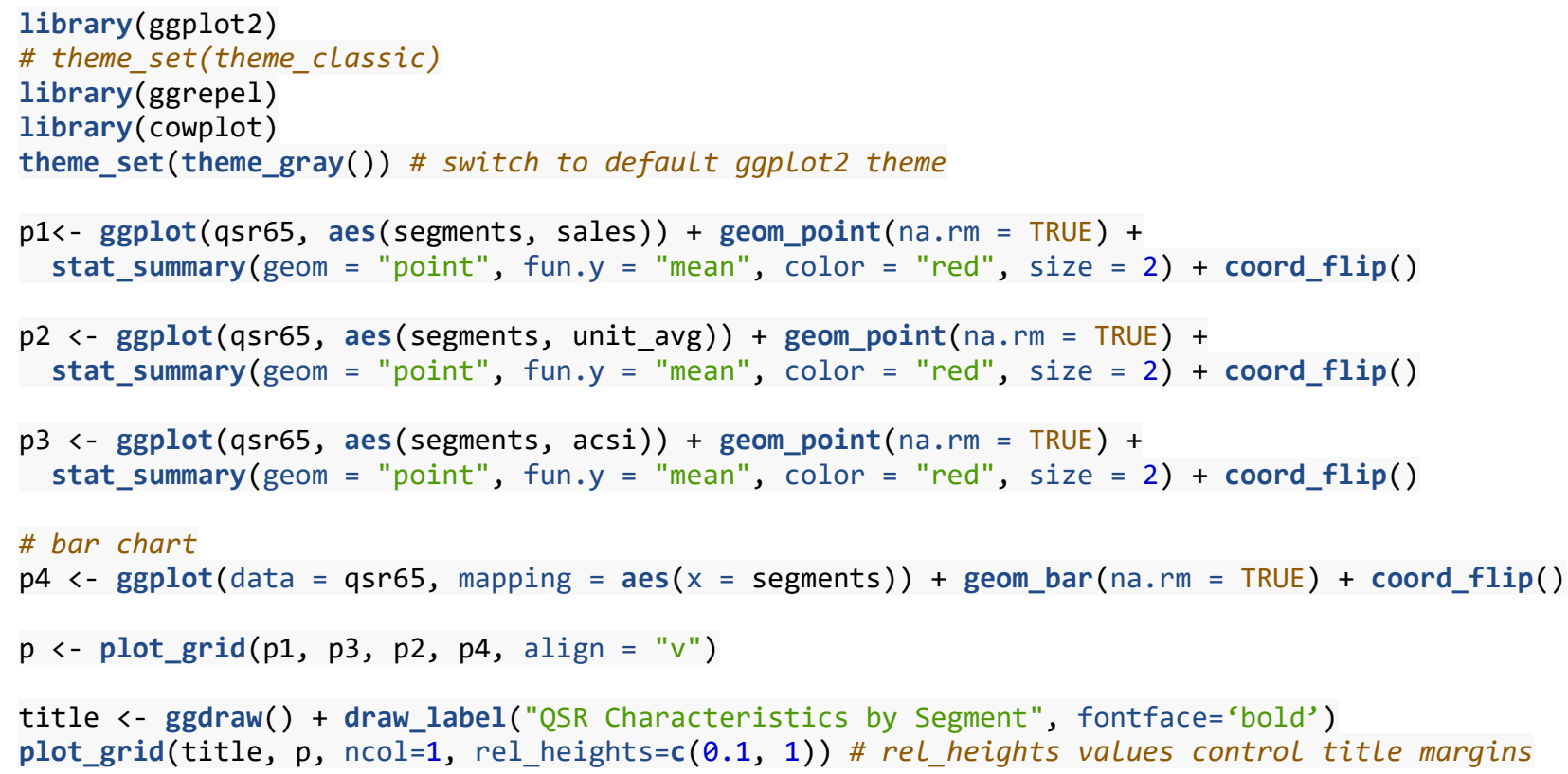




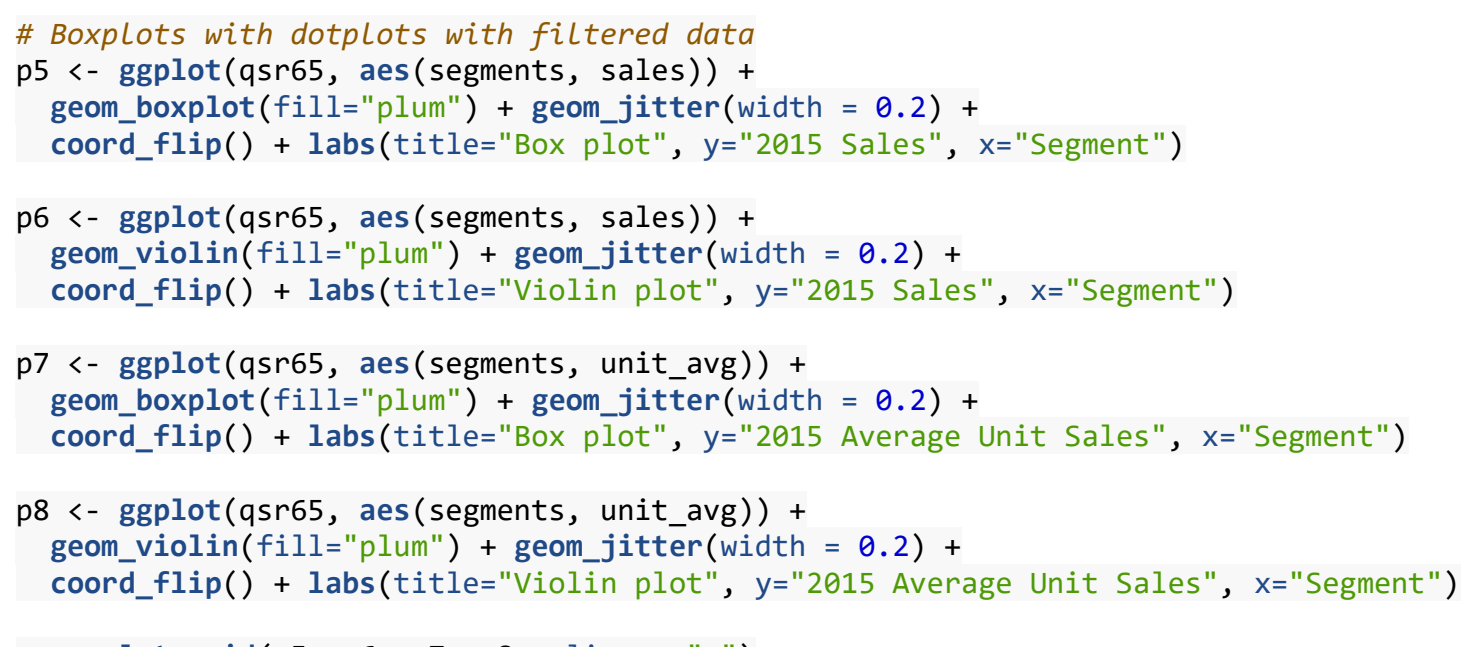

p <- plot_grid(p5, p6, p7, p8, align = "v")

title <- ggdraw() + draw_label("QSR Boxplots and Violin plots by Segment", fontface= 'bold') plot_grid(title, $\mathrm{p}, \mathrm{ncol}=1$, rel_heights $=\mathrm{c}(0.1,1))$ \# rel_heights values control title margins

p9 <- ggplot(qsr65, aes $(x=$ acsi, $y=$ sales, label = company, color=segments $))+$ geom_point (na.rm = TRUE, size $=2$, shape $=1)+$ ggrepel: :geom_text_repel(aes(label = company), size $=3)+$ geom_jitter (width $=0.1$, height $=0.1)+$ geom_smooth (method $=$ 'loess', color $=$ "blue", size $=1.5$, na.rm $=$ TRUE, se $=$ FALSE)

p10 <- ggplot(qsr65, aes $(x=$ acsi, y=unit_avg, label = company, color=segments $))+$ geom_point (na.rm = TRUE, size $=2$, shape $=1)+$ ggrepel: :geom_text_repel(aes $($ label $=$ company $)$, size $=3)+$ geom_jitter (width $=0.1$, height $=0.1)+$

title <- ggdraw() + draw_label("QSR Sales and Average Unit Sales by ACSI", fontface= 'bold') plot_grid(title, $p, \operatorname{ncol}=1$, rel_heights $=\mathrm{c}(0.1,1))$ \# rel_heights values control title margins

\# replace missing valuse for acsi with its average value qsr65\$acsi[is.na(qsr65\$acsi)] <- mean(qsr65\$acsi, na.rm = TRUE)

best_sales_in_segment <- qsr65 \%>\% group_by(segments) \%>\% filter(row_number $($ desc $(\operatorname{sales}))==1)$

p11 <- ggplot(qsr65, aes $(x=$ acsi, $y=$ sales, color=segments $))+$ geom_point (na.rm $=$ TRUE, $\operatorname{size}=3$, shape $=1$, data = best_sales_in_segment $)+$ ggrepel::geom_text_repel(aes $($ label $=$ company $)$, size $=3$, data = best_sales_in_segment $)+$ geom_jitter $($ width $=0.1$, height $=0.1$ )

\# Remove confidence intervals and extend regression Lines

p12 <- ggplot(qsr65, aes ( $x$ = acsi, $y=$ sales, color=segments $))+$ geom_point (na.rm $=$ TRUE, size $=3$, shape $=1$, data $=$ best_sales_in_segment $)+$ ggrepel::geom_text_repel( $\operatorname{aes}($ label $=$ company $)$, size $=3$, data $=$ best_sales_in_segment $)+$ geom_jitter (width $=0.1$, height $=0.1)+$ geom_smooth (method=lm, se=FALSE, fullrange=TRUE)

p <- plot_grid $(p 11, p 12$, ncol = 1)

title <- ggdraw() + draw_label("QSR Best Sales in Each Segment by ACSI", fontface='bold') plot_grid(title, p, ncol=1, rel_heights=c(0.1, 1)) \# rel_heights values control title margins

best_unit_avg_in_segment <- qsr65\% \% \% group_by (segments) \%>\% filter(row_number(desc(unit_avg)) ==1)

p13 <- ggplot(qsr65, aes (x = acsi, y=unit_avg, color=segments $))+$ geom_point(na.rm = TRUE, size $=3$, shape $=1$, data = best_unit_avg_in_segment) + ggrepel::geom_text_repel(aes (label = company), size $=3$, data = best_unit_avg_in_segment $)+$ geom_jitter (width $=0.1$, height $=0.1$ ) 


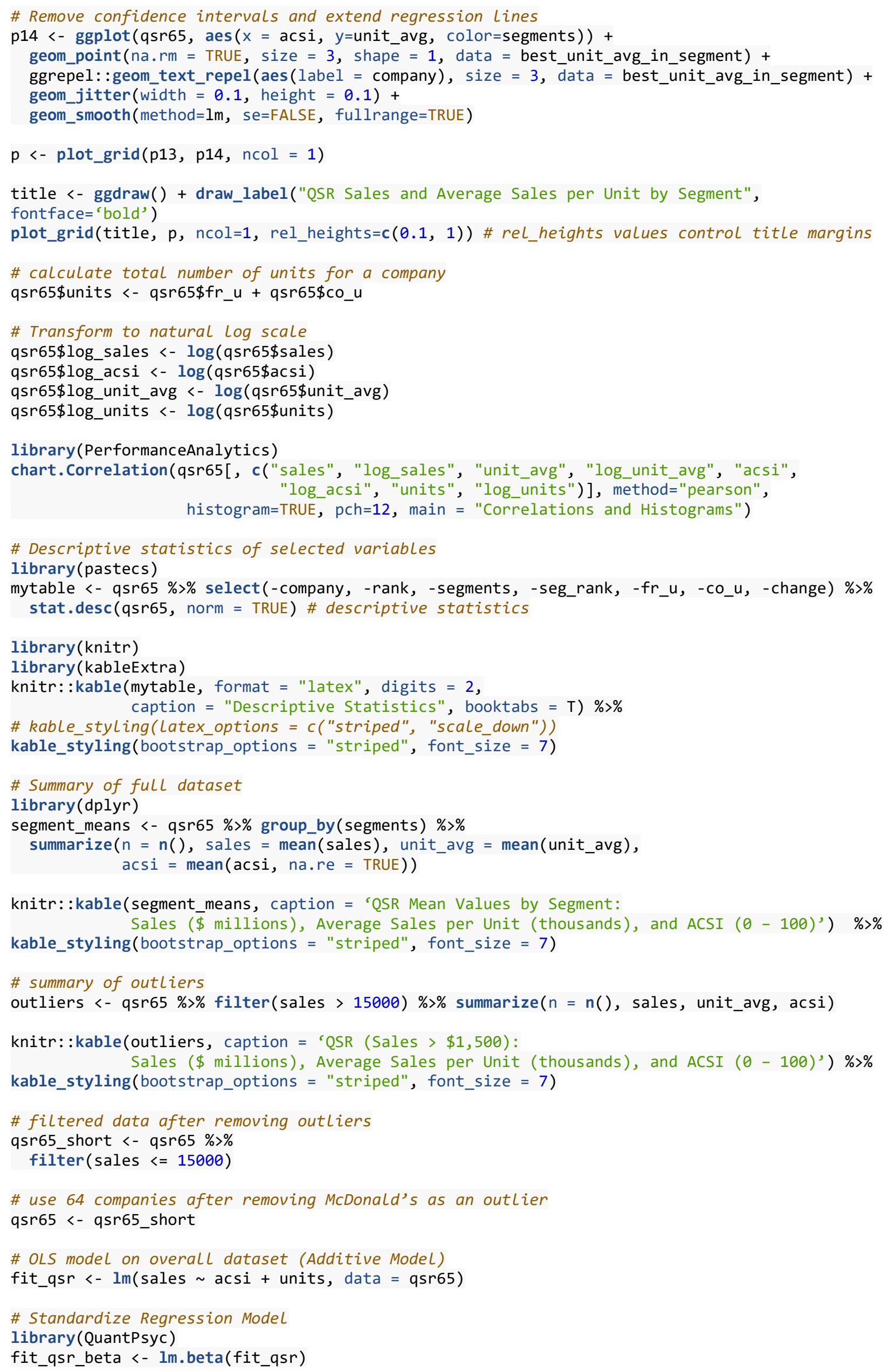




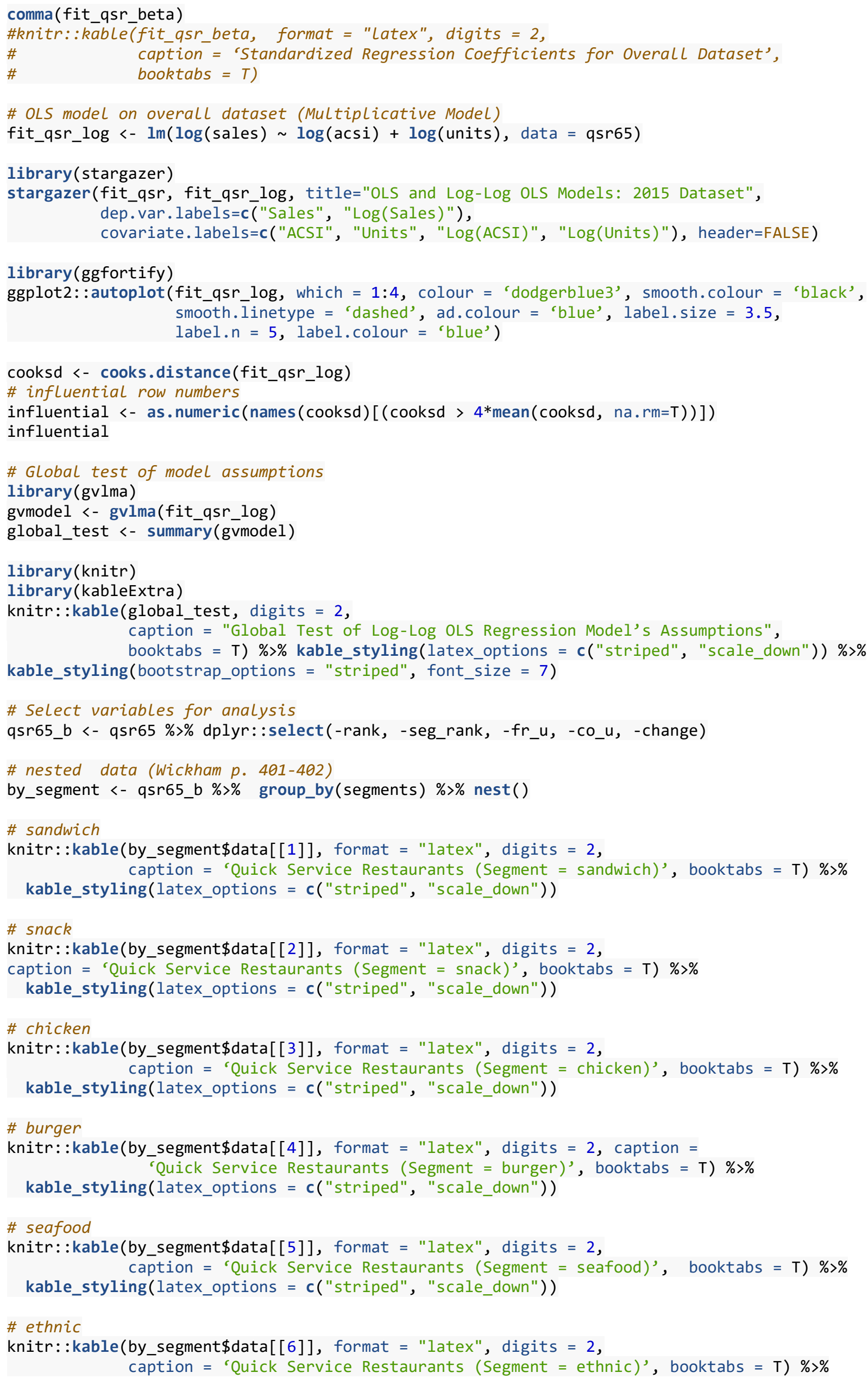




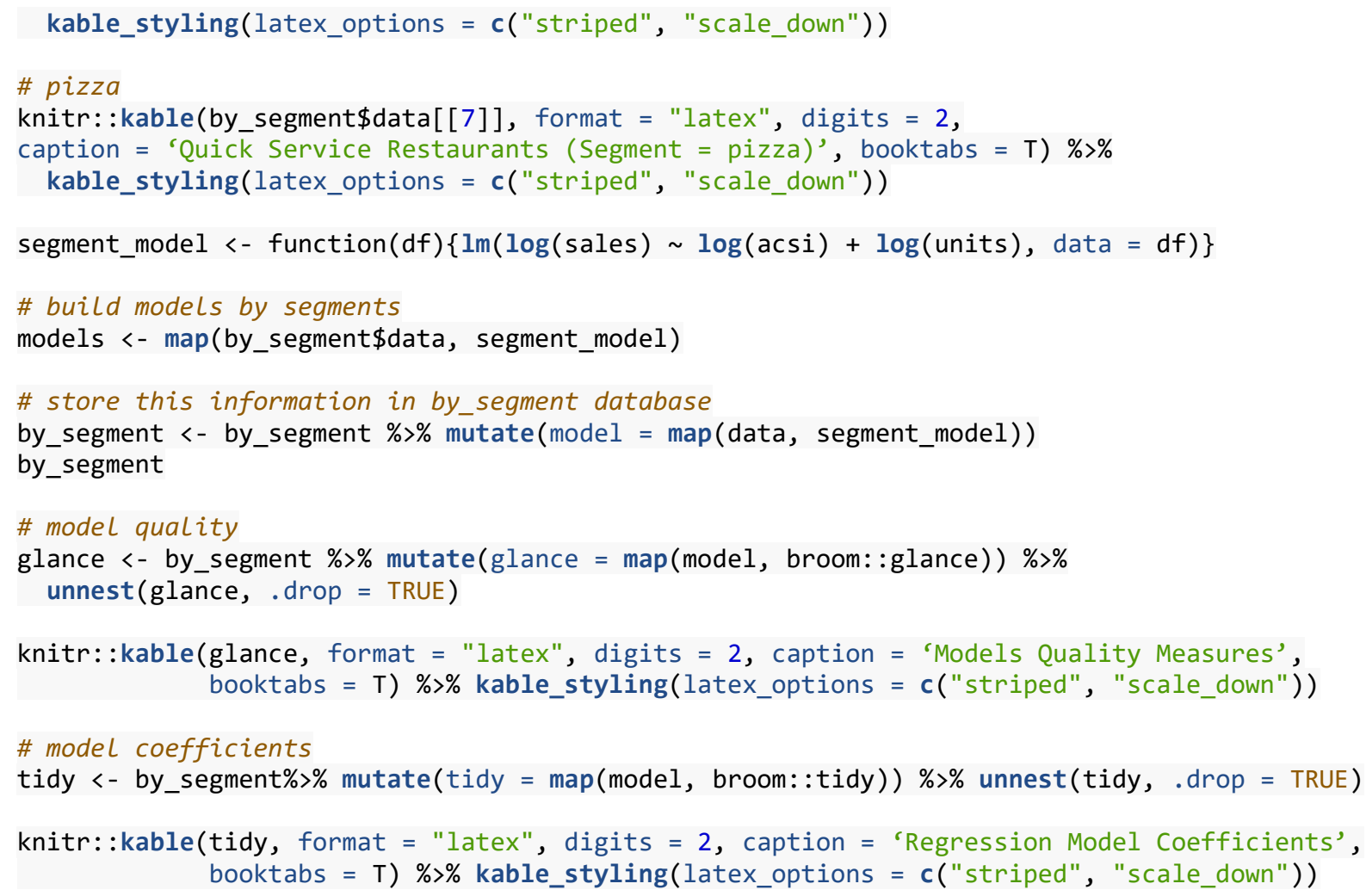

